San Jose State University

SJSU ScholarWorks

Master's Theses

Master's Theses and Graduate Research

Spring 2020

\title{
The Moderating Effects of Gender and Occupation on Age Discrimination in Hiring
}

Rachel Su Windsor

San Jose State University

Follow this and additional works at: https://scholarworks.sjsu.edu/etd_theses

\section{Recommended Citation}

Windsor, Rachel Su, "The Moderating Effects of Gender and Occupation on Age Discrimination in Hiring" (2020). Master's Theses. 5115.

DOI: https://doi.org/10.31979/etd.hg7k-fh6m

https://scholarworks.sjsu.edu/etd_theses/5115

This Thesis is brought to you for free and open access by the Master's Theses and Graduate Research at SJSU ScholarWorks. It has been accepted for inclusion in Master's Theses by an authorized administrator of SJSU ScholarWorks. For more information, please contact scholarworks@sjsu.edu. 


\title{
THE MODERATING EFFECTS OF GENDER AND OCCUPATION ON AGE DISCRIMINATION IN HIRING
}

\author{
A Thesis \\ Presented to \\ The Faculty of the Department of Psychology \\ San José State University \\ In Partial Fulfillment \\ of the Requirements for the Degree \\ Master of Science
}

by

Rachel Windsor

May 2020 
(C) 2020

Rachel Windsor

ALL RIGHTS RESERVED 
The Designated Thesis Committee Approves the Thesis Titled

THE MODERATING EFFECTS OF GENDER AND OCCUPATION ON AGE DISCRIMINATION IN HIRING

\author{
by \\ Rachel Windsor \\ APPROVED FOR THE DEPARTMENT OF PSYCHOLOGY \\ SAN JOSÉ STATE UNIVERSITY
}

May 2020

Dr. Megumi Hosoda Department of Psychology

Dr. Sandra Trafalis Department of Psychology

Dr. Valerie Carr Department of Psychology 


\title{
ABSTRACT \\ THE MODERATING EFFECTS OF GENDER AND OCCUPATION ON AGE DISCRIMINATION IN HIRING
}

\author{
by Rachel Windsor
}

Over the years, ageism in the workplace has become an important topic. However, it remains unclear whether and how gender and occupation relate to age discrimination in hiring decisions. The current study addresses this issue by investigating job suitability ratings and selection decisions by comparing two hypothetical job applicants who differ in age (younger vs. older) and gender (male vs. female) for two occupations (software engineer vs. nurse) in two industries (high-tech and healthcare). This study employed a $2 \times 2 \times 2$ incomplete mixed-factorial design, in which age was a within-subjects factor, and gender and occupation were betweensubjects factors. A total of 309 adults participated in the study via Amazon MTurk, and the final sample consisted of 250 participants after data cleaning. Among several findings, the most important results were that when a younger man competed against an older woman as software engineer applicants, he was rated as more suitable for the position, selected more often for the job, and more likely to be hired as a full-time employee. Conversely, when a younger woman competed against an older man for a nursing position, she received more favorable ratings (i.e., job suitability, interpersonal skills, and hiring selections) than him. These results suggest that hiring decisions may be jointly determined by age, gender, and occupation. For example, older female job applicants may be discriminatory targets as software engineers, whereas older male job applicants may be discriminated against as nurses. Organizations should make an effort to reduce biases in hiring decision making. 


\section{ACKNOWLEDGEMENTS}

First and foremost, I would like to thank my thesis committee for providing their expertise and guidance throughout this process. Specifically, I would like to express deepest gratitude to Dr. Megumi Hosoda for her endless support and encouragement, especially during my most difficult time of this journey. I truly cannot thank her enough for her time, energy, and commitment to my success during the entirety of this research. I will forever be grateful for her and her dedication to my growth. Her endless patience and wisdom helped me to achieve the best product I could ever create. I would like to thank my second reader Dr. Sandra Trafalis for providing me constructive feedback to polish my work. Finally, I would like to thank my third reader Dr. Valerie Carr, who continuously provide me mentorship ever since I was an undergraduate student here at San José State University. I am deeply thankful for her support throughout these years, teaching me how to learn and giving me a lot of opportunities to improve my research and technical skills such as using programming to conduct research and data analyses.

Thank you to my dear husband, Kristopher Windsor, who has supported me financially throughout all my years of higher education at San José State University and emotionally whenever I need a break before I keep on going. Thank you, my parents, who always love me unconditionally, supporting my dreams, no matter where they take me. More importantly, without their help for taking care of my baby, it is impossible for me to finish this degree. Thank you for my friends and in-laws' continuous support and encouragement. To my dear one-year-old son, I hope mommy sets up a great example for you to become a person who never give up your dream but keep on trying with hard work, self-discipline and perseverance. 
Finally, a special thanks to my cohort of 2018. You are some of the most

extraordinary people I have met, and I cherish the experience of learning from all of you and learning with you. Cannot wait to see what we all will achieve from here! 


\section{TABLE OF CONTENTS}

List of Tables

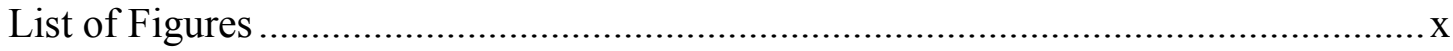

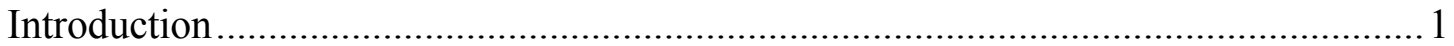

Age Discrimination Prevalence and Practices ...................................................... 3

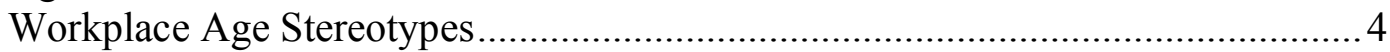

Poor performance and low productivity. ..................................................... 5

Lack of motivation and interest in organizational goals. .............................. 6

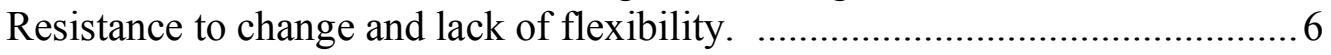

Age Discrimination in a Recruitment and Hiring Setting ..................................... 7

Recruitment Ageism in High-Tech and Healthcare Industries ............................. 9

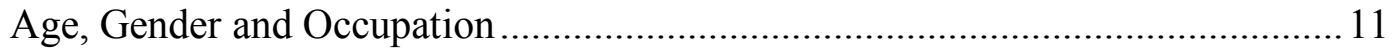

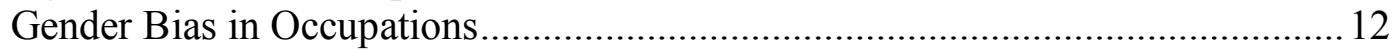

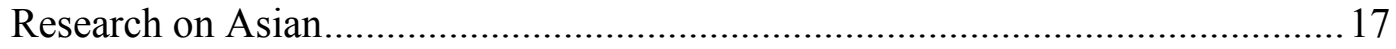

Self-Report Perceived Discrimination Survey versus Experimental Study........... 18

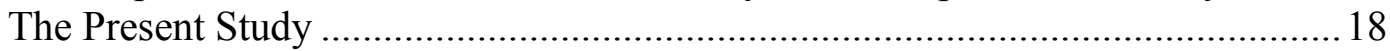

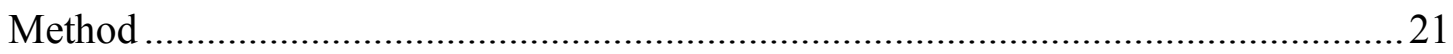

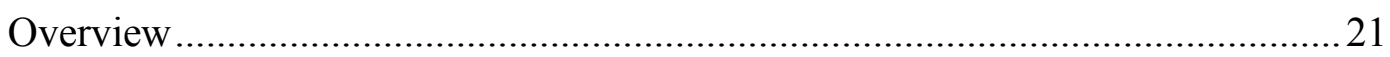

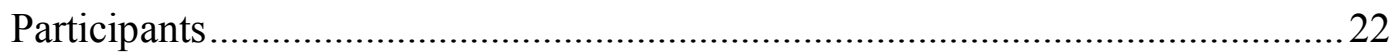

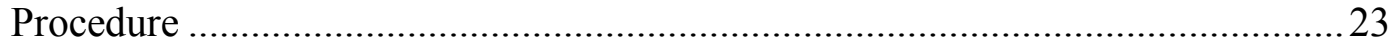

Experimental Manipulations and Stimulus Materials .......................................24

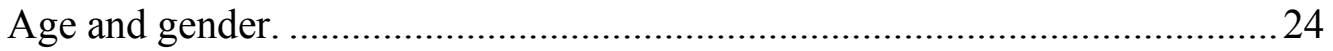

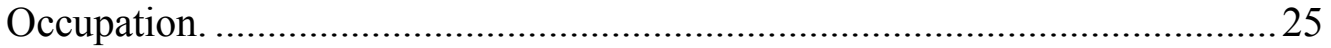

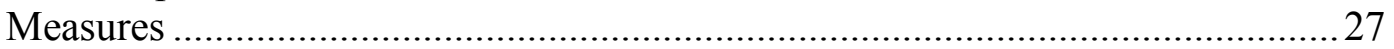

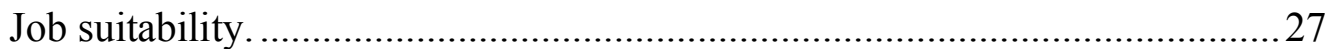

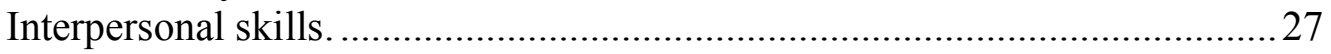

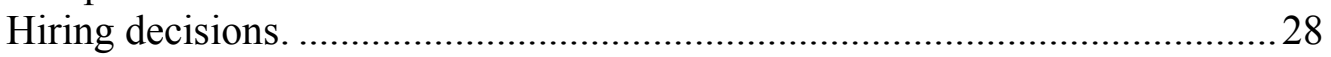

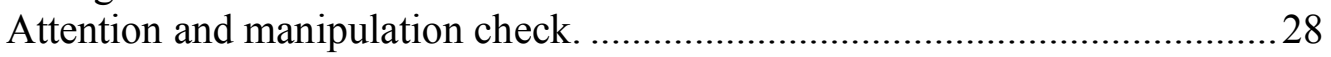

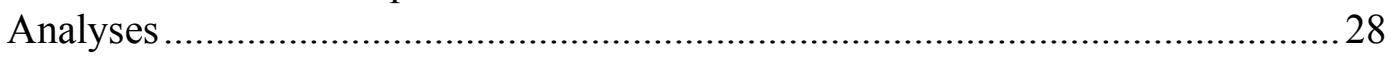

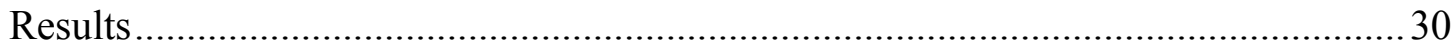

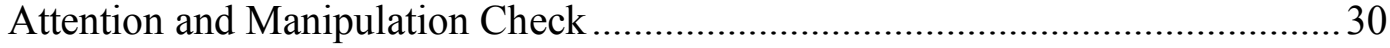

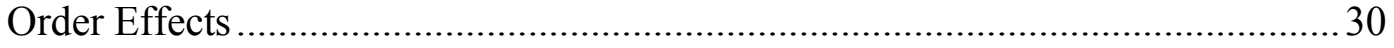

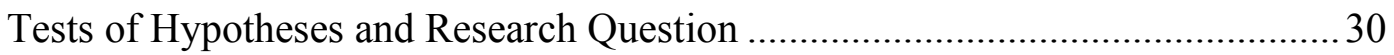

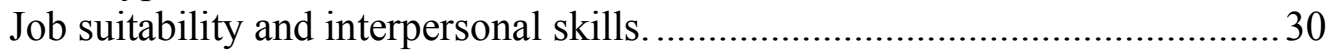

Age effect in two occupations (software engineer and nurse). ......................3 32

Interaction among age, gender and occupation. ..............................................33

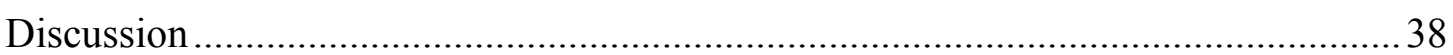

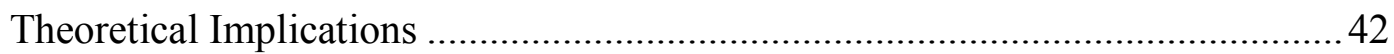

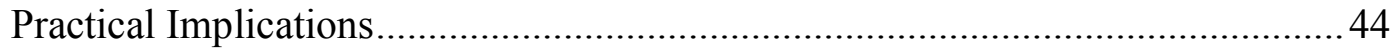

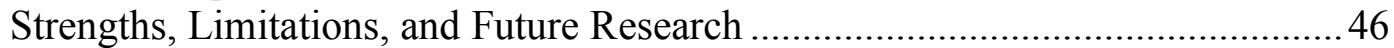

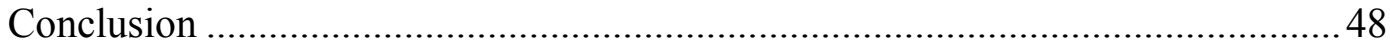




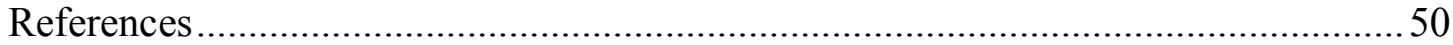

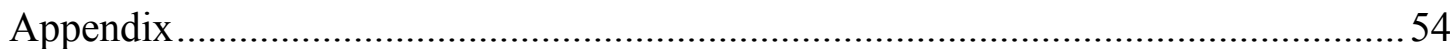




\section{LIST OF TABLES}

Table 1. Experimental Design Diagram.....

Table 2. Comparisons of Job Suitability and Interpersonal Skills for Study

Conditions .....

Table 3. Number of Applicants Selected and Chi-Square Tests for Rating as More Qualified and Hiring for a Full-Time Position by Study

Conditions 


\section{LIST OF FIGURES}

Figure 1. Job applicants selected to be hired as software engineers...............36

Figure 2. Job applicants selected to be hired as nurses..................................3 


\section{Introduction}

Unlike members of particular groups that are more prone to certain discrimination (e.g., race, sex), everyone is susceptible to ageism at some point in life and faces the inevitable reality of aging every day (e.g., $\mathrm{Ng} \&$ Feldman, 2008; Posthuma \& Campion, 2009; Vasconcelos, 2015). Moreover, age-related issues (i.e., ageism) in the employment context have become more critical than ever before because there is a dramatic shift in workforce demographics and multiple generations are working within the same workplace (e.g., Cortijo, McGinnis, \& Şişli-Ciamarra, 2019; Fisher, Truxillo, Finkelstein, \& Wallace, 2017; Hanrahan, Lindeman, \& Finkelstein, 2017).

Statistics have shown that there is a large workforce of middle-aged and older adults (i.e., aged 40 and above) in the economic system of the United States. In addition, the number of aging workers is expected to grow in the near future (Fisher et al., 2017; Toossi \& Torpey, 2017). According to U.S. Bureau of Labor Statistics (2019b), 53.6\% of the workforce in 2018 was 40 years of age and older; that is, more than 86 million people who were employed in 2018 fell into this age category. Moreover, U.S. Bureau of Labor Statistics projected that by 2024, the number of older workers, specifically, aged 55 and older, would continue to grow more than their counterparts, who are younger than aged 55, in the labor force (Toossi \& Torpey, 2017).

Furthermore, this trend is more universal than being a unique situation in a single country (i.e., the United States). Studies have shown that other developed western countries such as Canada, England, Belgium, Italy, Germany, and Australia and newly industrialized countries like Brazil and China are facing the same challenge of an aging 
population in the labor market (e.g., Baert, Norga, Thuy, \& Van Hecke, 2016; Fisher et al., 2017; Heywood \& Jirjahn, 2016; Lagacé, Beeck, \& Firzly, 2019). Hence, aging in the labor force is a global issue.

As the workforce ages universally, it is important and critical to focus on the topic of ageism for the reasons listed below. Ageism in the context of employment is regarded as the workplace discriminatory practices that influence older employees in a negative manner, which result from some widespread misinformation and false assumptions about older adults (Posthuma \& Campion, 2009; Vasconcelos, 2015). As Vasconcelos (2015) used ageism and age discrimination interchangeably, I followed the same approach in this paper.

From the perspective of society, the aging workforce plays a critical role in both economic growth and stability (e.g., Cortijo et al., 2019; Fisher et al., 2017; Posthuma \& Campion, 2009; Riach \& Rich, 2010). As stated previously, those aged 55 and above are projected to outnumber their younger counterparts by 2024 in the United States (Toossi \& Torpey, 2017). In other words, within the next four years, the majority of the U.S. population who contribute to the economic system are older employees. As older people remain in the workforce, not only will they help to make financial contributions to but also reduce strain on social security systems because they can live on their own earnings instead of relying on social welfare (e.g., Cortijo et al., 2019; Drydakis, MacDonald, Chiotis, \& Somers, 2018; Posthuma \& Campion, 2009). In spite of this, age discrimination still prevails in the society and it is problematic because it supports unfair, 
intolerant, and detrimental views and perceptions against older individuals (Vasconcelos, 2015).

From the perspective of organizations, ageism may lead to devastating impacts on both employees and the whole organization (Cortijo et al., 2019; Hanrahan et al., 2017; Lagacé et al., 2019; Posthuma \& Campion, 2009; Vasconcelos, 2015). First, employment discrimination on a basis of age makes employers miss opportunities to attract and retain older skilled and productive workers as well as take advantage of an age-diverse workforce, which may in turn lead to negative organizational outcomes such as lower productivity, retention, company growth, financial performance, and return on investment (Cortijo et al., 2019; Hanrahan et al., 2017; Posthuma \& Campion, 2009; Vasconcelos, 2015). Second, age discrimination makes business prone to financial loss due to legal liability and reputation damage (Cortijo et al., 2019; Ng \& Feldman, 2012; Posthuma \& Campion, 2009). Third, with regard to corporate social responsibility, organizations have a moral obligation to combat this societal problem (i.e., ageism) by making an extra effort to reduce workplace discrimination against older employees rather than merely comply to laws and regulations (Cortijo et al., 2019; Vasconcelos, 2015). Therefore, ageism in the workplace has a profound impact on both society and organizations. For this reason, it is important to look into the discrimination prevalence and practices related to age.

\section{Age Discrimination Prevalence and Practices}

Despite the fact that in the United States, the Age Discrimination in Employment Act of 1967 (ADEA) protects job applicants and employees who are 40 years of age or older 
from employment discrimination on a basis of age, U.S. Equal Employment Opportunity Commission (EEOC) has received about 400,000 complaints of age discrimination in employment in the past 20 years. Furthermore, in 2018, over one fifth of EEOC charges fell in age category (EEOC, 2020). A study conducted by Chou and Choi (2011) revealed that more than $80 \%$ of older individuals who were 50 years old and above experienced discriminatory treatment in an employment context at least once a year.

In addition, prior research shows that age plays a significant role in managerial discrimination from talent acquisition to talent management, which includes recruitment and selection, performance evaluation, training, promotion, and retention (e.g., $\mathrm{Ng} \&$ Feldman, 2008, 2012; Fisher et al., 2017; Posthuma \& Campion, 2009; Vasconcelos, 2015). The underlying mechanism that leads to these discriminatory practices is largely due to age stereotyping in the workplace (Fisher et al., 2017; Vasconcelos, 2015). In the following section, I will describe some common findings of workplace age stereotypes.

\section{Workplace Age Stereotypes}

Workplace age stereotypes refer to beliefs and expectations about workers on the basis of their age (Posthuma \& Campion, 2009; Vasconcelos, 2015). Posthuma and Campion (2009) posit that ageism in the work settings arises from age stereotypes as most of which ascribe negative attributes to older employees. These workplace age stereotypes include: old people have poor performance and low productivity; they lack motivation and interest in organizational goals; and they are resistant to change and lack flexibility (e.g., Hanrahan et al., 2017; Lagacé et al., 2019; Ng \& Feldman, 2012, 2013; Posthuma \& Campion, 2009; Vasconcelos, 2015). 
Moreover, these negative assumptions about older workers intertwine together and act at a subtle and unconscious level to influence people's judgments of older individuals (Hanrahan et al., 2017; Posthuma \& Campion, 2009; Vasconcelos, 2015). Nonetheless, these age-based biases are often inaccurate with the support of several meta-analyses and other literature reviews conducted by different scholars (e.g., Ng \& Feldman, 2008, 2012, 2013; Posthuma \& Campion, 2009).

Poor performance and low productivity. Past empirical studies demonstrate little evidence that older employees have lower job performance or productivity than their younger counterparts with objective measures (e.g., Fisher et al., 2017; Hanrahan et al., 2017; Posthuma \& Campion, 2009; Riach \& Rich, 2010). Ng and Feldman (2008)'s meta-analysis illustrates that age is not associated with the performance of core tasks rated by peers or others. Notably, Posthuma and Campion (2009) highlight that individual differences are more significant in terms of the association between age and job performance. Put differently, there is a larger difference in job performance within the age groups than between age groups (Posthuma \& Campion, 2009).

In contrast, older adults make a great contribution to other domains of job performance. That is, they engage in more safety and organizational citizenship behaviors (OCBs; Ng \& Feldman, 2008). OCB is defined as "performance that supports the social and psychological environment in which task performance takes place" (Organ, 1997, p.95). In a related vein, older workers engage in fewer counterproductive work behaviors (CWBs; e.g., workplace aggression, on-the-job substance use, tardiness; Ng \& Feldman, 2008). Furthermore, Heywood and Jirjahn (2016) review studies conducted worldwide 
and find that there is no link between age and productivity. Accordingly, research shows that it is an erroneous workplace stereotype that older employees have poor performance and low productivity.

Lack of motivation and interest in organizational goals. There is a considerable amount of research evidence that discount this stereotype (Armstrong-Stassen \& Schlosser, 2011; Ng \& Feldman, 2012; Vasconcelos, 2015). In particular, Vasconcelos (2015) offers a counterargument that older persons are as motivated as younger ones to achieve organizational goals. Aligned with the same view, Armstrong-Stassen and Schlosser (2011) posit that older employees desire to make a meaningful contribution to their organization. In a similar vein, Ng and Feldman (2012)'s meta-analysis shows that age is positively related to job motivation and involvement. Besides, older employees have a higher level of organizational commitment than their younger competitors (Vasconcelos, 2015). Hence, this stereotype is not supported by empirical studies.

Resistance to change and lack of flexibility. Employers assume that older employees are less adaptable and flexible so that they are more likely to resist to organizational change (e.g., Hanrahan et al., 2017; Ng \& Feldman, 2012; Posthuma \& Campion, 2009; Vasconcelos, 2015). However, Ng and Feldman's (2012) meta-analysis show that this assumption is not true based on empirical findings. Along the same line, Vasconcelos (2015) also refutes this false assumption by pointing out that people of all different ages are uncomfortable about organizational change on the grounds of fear of uncertainty, whereas older workers become the scapegoats (i.e., being the targets of the blame) in this case. Furthermore, just the opposite, a study shows that older employees 
are more ready and active in organizational change process than their younger counterparts (Vasconcelos, 2015).

In sum, workplace age stereotypes are often negative and false assumptions about older employees (e.g., Posthuma \& Campion, 2009; Vasconcelos, 2015). Most of them are incongruent with empirical evidence (Ng \& Feldman, 2008, 2012, 2013). However, they operate at a subtle level as an antecedent of ageism, which negatively influences older individuals at all levels of employment process (Fisher et al., 2017; Hanrahan et al., 2017; Ng \& Feldman, 2008, 2012, 2013; Posthuma \& Campion, 2009; Vasconcelos, 2015).

As people remain in labor force until later ages and older individuals apply for new jobs throughout different stages of life span, it is essential to explore whether there is an ageism in the recruitment setting (Fisher et al., 2017). In the subsequent section, I will discuss age discrimination in a recruitment and hiring setting.

\section{Age Discrimination in a Recruitment and Hiring Setting}

Prior research has shown that overall, there is a preference for younger job seekers over their older counterparts in hiring choices (Fisher et al., 2017). In their meta-analysis, Bal, Reiss, Rudolph, and Baltes (2011) found a medium-sized negative effect of age, demonstrating that older workers fared worse in personnel decisions with regard to general evaluations, interpersonal skills and selection. In addition, Vasconcelos (2015) conducted a literature review on ageism and found that recruiters applied an age limit (i.e., around aged 45 and above) such that they clearly disfavored those job applicants who were over the age limit in the labor market. This case was especially apparent in the 
high-tech industry, wherein many tech companies were run by younger generations that held negative stereotypes against older individuals (Vasconcelos, 2015).

Furthermore, scholars have reviewed literature and summarized that older job candidates face more hurdles to overcome in order to rejoin the workforce (e.g., Hanrahan et al. 2017; Fisher et al., 2017; Posthuma \& Campion, 2009; Vasconcelos, 2015). A meta-analysis conducted by Wanberg, Kanfer, Hamann, and Zhang (2016) shows that there is a negative relationship between age of a job seeker following job loss and reemployment status. That is, older job seeks are less likely to be reemployed. They also find that this negative relationship becomes magnified for those over aged 50. These findings corroborate with the report by the U.S. Government Accountability Office (2012) that the number of workers aged 55 and older experiencing long-term unemployment has grown substantially since 2007. Other researchers find the same situation in other western countries, that is, older individuals have much less career mobility and opportunity due to age discrimination in the hiring context (e.g., Drydakis et al., 2018; Heywood \& Jirjahn, 2016). It is noteworthy that Heywood and Jirjahn (2016) have found that even if being hired, in comparison with their younger counterparts, older workers are less likely to be selected as full-time employees.

In addition, Posthuma and Campion (2009) have argued that industries may play a role in the average age of job applicant pool, which in turn influences decision-making within the work domain. Specifically, some industries (e.g., high-tech, retails, finance, insurance) may function as an antecedent of age discrimination in the labor market (Posthuma \& Campion, 2009; Slay Ferraro, Prussia, \& Mehrotra, 2018; Vasconcelos, 
2015). One reason is that age stereotyping is more severe in these industries (Posthuma \& Campion, 2009). For example, there is a widespread assumption that older adults are not tech-savvy, that is, they are not proficient in the use of technology such as computers and new software (Hanrahan et al., 2017; Ng \& Feldman, 2013). Thus, older adults are stereotyped as less competent or capable than their younger competitors (Posthuma \& Campion, 2009). Additionally, these industries shape an image that there is a preference for younger individuals (Posthuma \& Campion, 2009; Slay Ferraro et al., 2018). As a result, older job applicants are hesitant or intimidated switching their career into these industries, which, in turn, negatively impacts older adults' career mobility (Slay Ferraro et al., 2018). Accordingly, scholars (e.g., Fisher et al., 2017; Posthuma \& Campion, 2009) have suggested that industries may moderate the effect of age discrimination in the employment context. In the next section, I will discuss why it is important to pay particular attention to recruitment ageism in two specific industries (i.e., high-tech and healthcare).

\section{Recruitment Ageism in High-Tech and Healthcare Industries}

Studies on age discrimination during a recruitment process have been conducted in manufactory, food service (e.g., restaurant), retail, office work, and accounting settings, but the high-tech and healthcare industries have never been explored (e.g., Drydakis et al., 2018; Riach \& Rich, 2010). This is unfortunate because the high-tech industry has become a major source of U.S. economic growth in the past couple of decades and involves millions of jobs (EEOC, 2016). Likewise, healthcare is another fast-growing industry that provides millions of job opportunities in the U.S. economy (Torpey, 2014). 
Consequently, it is important for researchers and policyholders to understand more about these two industries.

Furthermore, one of the major occupations in the high-tech industry is software developer (engineer), whereas nursing is at the heart of the healthcare industry (EEOC, 2016; National Council of State Boards of Nursing, 2018). According to Bureau of Labor Statistics (2019d; 2019e), employment opportunities for software engineers and nurses are projected to grow at a much faster rate (i.e., $21 \%$ and $12 \%$, respectively) than average from 2018 through 2028. Hence, it is essential to study these two specific occupations on potential age discrimination.

In regard to the recruitment arena, Hanrahan et al. (2017) have suggested that older job seekers are less likely to gain employment opportunities in the industries that are fastpaced (e.g., high-tech industry) because they are viewed as less adaptive. In fact, big tech companies like Google and Facebook have paid millions of dollars to settle age discrimination lawsuits against older job applicants (Hern, 2019; Terrell, 2019). In addition, Posthuma and Campion (2009) stated, "certain jobs, including information technology jobs, were considered inappropriate for older workers" (p.166) for the reason that older individuals do not match with the age norm of these jobs or professions.

On the other hand, around one million of registered nurses currently employed in the United States are over 50 years old (Haddad \& Toney-Butler, 2019). Moreover, the median age of registered nurses is around 44 years old (Data USA, 2019). As a result, people may perceive job applicants of aged 40 to 50 are matched with the right age of this occupation such that workplace ageism may be less for a nursing job. Taken together, 
potential age discrimination in the recruitment setting may be more severe for job applicants of software engineer than for those of nurse. In accordance with this, the present study tests the following hypothesis.

Hypothesis 1. There will be an interaction of age and occupation on the hiring decision-making when the gender is held constant such that when the occupation is a software engineer, the ratings of (H1a) job suitability and (H1b) interpersonal skills will be higher for younger applicants than for older applicants, whereas when the occupation is a nurse, the ratings of (H1c) job suitability and (H1d) interpersonal skills will be similar between both younger and older job applicants. Put another way, age discrimination in the recruitment context is stronger for job applicants of software engineer than those of nurse.

In addition to industry type, researchers have suggested that another potential moderator of age discrimination is gender due to the interactive effect of different stereotyping (e.g., Posthuma \& Campion, 2009). In the following section, I will discuss the rationale of potential three-way interactions of age, gender and occupation.

\section{Age, Gender and Occupation}

Scholars (e.g., Fisher et al., 2017; Posthuma \& Campion, 2009) have called for research attention to investigate age discrimination in different contexts. More specifically, the effects of age and gender on managerial decisions with respect to different occupations should be examined as these factors may interact with one another to exacerbate age discrimination (Fisher et al., 2017; Posthuma \& Campion, 2009; Potter et al., 2019). Indeed, Fekedulegn et al. (2019) conducted a study to examine the 
prevalence of workplace discrimination through a large national sample $(N=4,798)$ of older U.S. workers, who were aged 48 years old and above. They found that overall, in comparison to men, women experienced 53\% more discrimination. Nevertheless, gender may interact with occupation that influences employment-related decisions for specific occupations (i.e., software engineer and nurse) due to occupational gender biases.

\section{Gender Bias in Occupations}

Kay, Matuszek, and Munson (2015) argued that occupational gender biases persisted prevalently in the United States, which in turn thwarted the minority gender in some specific professions (e.g., women as engineers or men as nurses). In light of this, they suggested that people relied on stereotypes of certain occupations to make decisions, which further reinforced gender segregation for occupational choices, opportunities and compensations.

Furthermore, Kay et al. (2015) explained that there were two possible causes of occupational gender biases. One was that according to a self-fulfilling prophecy, which is defined as that people behave in a way that is in accordance with what they believe (Merton, 1968), if individuals fell into the trap of stereotyped expectations of what career path they should pursue based on their gender, they might limit their aspirations and abilities in the occupations, wherein they believed to be not matched with their gender.

The other possible cause was that people (e.g., decision-makers) might utilize stereotypes to decide what to do or how to act, especially in the situations where the available information was limited. Kay et al. (2015) contented that "stereotypes about abilities are a common source of bias" (p. 3820) such that a gender with a small 
proportion of representations in a profession (e.g., female engineers or male nurses) might be perceived to less competent.

Among many occupations, software engineer and nurse are two exemplar occupations that are dominated by a single gender. As a matter of fact, according to U.S. Bureau of Labor Statistics (2019a), over 80\% of software developers (engineers) are male, whereas their female counterparts are only made up for $19.3 \%$. In contrast, $88 \%$ of registered nurses employed in 2018 are female. Hence, software engineers are a male-dominated profession, whereas nurses are a female-dominated profession.

Further, Kay and colleagues (2015) conducted a study of Google images search for different occupations and presented evidence that people preferred male representations (images) for male-dominant occupations and females for female-dominant occupations. Likewise, an image of an individual whose gender matched with the majority of a profession was rated as more professional-looking and such image was selected more as a preferred image search result. Accordingly, there is a gender stereotype for a certain type of occupations. Thus, taking the above information of U.S. Bureau of Labor Statistics with regards to the two occupations (i.e., software engineer and nurse) into account, people may perceive men are more suitable for being software engineers, while women are more suitable for being nurses.

In all, when it comes to the occupations of software engineer and nurse, age and gender may exert different impacts on employment decision-making because of age and gender stereotyping. As mentioned earlier, being old may be considered as an undesirable characteristic of job seekers because prototypical new hires or trainees are often expected 
to be young (Hanrahan et al., 2017). However, another characteristic (i.e., gender) of job candidates may be advantaged or disadvantaged depending on the occupations they apply. That is, men may be put in a favorable position for a software engineering job, whereas they may be put in an unfavorable position for being nurses. Likewise, being female may be considered as undesirable in the high-tech industry but desirable in the healthcare industry. Consequently, there may be double discrimination against older women as job applicants of software engineers and double discrimination against older men as job applicants of nurses. This is also aligned with the duel discrimination approach such that two different types of bias (i.e., age and gender) have independent, additive effects on decision-making (Hosoda, Stone, \& Stone-Romero, 2003).

Conversely, Potter and colleagues (2019) argued that discrimination experienced by individuals with multiple minority status cannot be summed through their collective impact (e.g., Asian + old + woman $\neq$ Asian old woman) based on the evidence of intersectionality. Intersectionality refers to the interaction of individuals' multiple social identities (e.g., race, age, gender) on the complex inequalities experienced, for the reason that the experiences of individuals or groups cannot be characterized by prioritizing one aspect of their identity (Potter et al., 2019). For instance, being young or old is one aspect of a person's social identity (i.e., age) and being male or female is another aspect of his or her social identity (i.e., gender). Instead of focusing on one aspect (e.g., age) or the other (e.g., gender), different aspects of one's identity should be considered as a whole, which Potter et al. (2019) called as "multiple dimensions of identity." 
Along the same lines, Potter and colleagues (2019) posit that multiple dimensions of identity (e.g., race, gender, age, socioeconomic status) interdependently shaped individuals' experiences across a wide range of different contexts such as educational, employment, and healthcare settings. The same authors have found several different twoway interactive effects of sociodemographic characteristics on perceived discrimination and on the attributions (i.e., cause or source) to the discrimination. For example, participants' gender (one dimension of identity) interacted with their socioeconomic status (SES, another dimension of identity) on the attribution of age to discrimination (i.e., perceiving age as the cause of discrimination). More specifically, women with low SES were found to be more likely to perceive that age was the cause of the discrimination against them than men with low SES, whereas men with high SES were more likely to endorse age as the cause of discrimination than women with high SES. Besides, they suggested that men in certain sectors of workforce (e.g., high-skill occupations) might perceive age as a more salient factor of discrimination than women.

Additionally, Potter et al. (2019) have argued that individuals with multiple social identity categories may experience both advantages and disadvantages depending on their reference group. For example, old White women may experience oppression in comparison to old White men, yet may be privileged relative to old women of other racial groups. Moreover, when contextual factors (e.g., occupations, industries) are taken into consideration, the disparities caused by the interaction of multiple dimensions of identity (e.g., age, race, gender) may be more complex than simple interactions of social identities (Potter et al., 2019). Taken together, whether an individual experiences inequality or not, 
depends not only on his or her reference group but also on the setting in which he or she is. In light of this, the present study tests the following hypothesis.

Hypothesis 2. Both age and gender will play a role in hiring decision-making for the two different occupations (i.e., software engineer and nurse). More specifically, as for a high-tech job (i.e., software engineer), when a younger man and an older woman are compared, the younger man will be rated higher on (H2a) job suitability and (H2b) interpersonal skills; (H2c) selected more often for the job; and (H2d) more likely to be hired as a full-time employee than his competitor (i.e., the older woman). By contrast, in regard to a healthcare job (i.e., nurse), when a younger woman competes against an older man, the younger woman will be rated higher on (H2e) job suitability and (H2f) interpersonal skills; (H2g) considered more qualified (i.e., being selected more); and (H2h) more likely to be hired as a full-time employee than the older man. In addition, the current study also makes an attempt to answer the following research question.

Research question. Will the effects of gender and occupation counteract to diminish age discrimination?

More specifically, there may be no difference in terms of discrimination between a younger woman and an older man as job applicants of software engineers. The rationale for this is that, given that the occupation is a software engineer, the younger woman may experience an advantage of being young but a disadvantage of being female, whereas the older man may experience oppression for being old but may enjoy privilege for being male such that in this context (e.g., being job applicants of software engineers), the 
advantages and disadvantages experienced by a younger woman or an older man may balance out, reducing or eliminating the effect of discrimination. The same rationale applies to the situation where a younger man and an older woman compete against each other as job candidates of nurses so that there may be no difference in terms of discrimination between them.

Potter et al. (2019) have called for future work on how the intersections of personal and contextual factors contribute to discrimination. In fact, the same authors have argued that multiple unconcealable stigmatized characteristics (e.g., Asian old women) may function as the attributions to elevated discrimination because of the minority status of race, age, and gender. I have discussed the effects of age and gender on stereotyping in the workplace previously. Next, I will briefly review the effect of race on employment discrimination.

\section{Research on Asians}

Most studies of workplace discrimination have focused on the major racial minority Blacks (e.g., Drydakis et al., 2018; Fekedulegn et al., 2019; Nunez-Smith et al., 2009). However, little attention has been paid to other racial backgrounds. For this reason, researchers (e.g. Potter et al., 2019) have called for more research attention on discrimination of other racial minority groups (e.g., Asian or Hispanic) as Asians or Latinx might experience mistreatment dissimilar from Blacks.

According to U.S. Bureau of Labor Statistics (2019a), over one third of software engineers (i.e., 35.4\%) employed in 2018 were Asians, while there were approximately 300,000 Asian nurses in labor force of 2018. Furthermore, Nunez-Smith and colleagues 
(2009) found that Asian was the second largest racial group (only second to Blacks) that experienced employment discrimination as physicians. More specifically, over the course of their medical career, almost a half (i.e., 45\%) of Asian physicians reported that they had experienced discrimination because of their race (Nunez-Smith et al., 2009).

Therefore, this study employed Asian job applicants as stimuli to contribute to the current literature. In addition to this, another noticeable issue in the existing literature of discrimination is that most studies employed self-report perceived discrimination survey rather than other research methods (e.g., experimental studies). In the next section, I will shortly explain why I would like to adopt an experimental approach.

\section{Self-Report Perceived Discrimination Survey versus Experimental Study}

There is extensive research on self-reported discrimination (Potter et al., 2019). A majority of earlier studies used self-report surveys to measure perceived discrimination (e.g., Fekedulegn et al., 2019; Nunez-Smith et al., 2009). Yet, Potter et al. (2019) argued that self-report perceived discrimination survey might inflate the effect of discrimination due to the nature of the question asked. In other words, studies, which ask participants to rate on a Likert-scale "to what extent have you been discriminated because of your age," may result in an inflated agreement of age discrimination because it is a leading question (Potter et al. 2019). Hence, it is necessary to conduct an experimental study to examine whether age discrimination exists in the context of workplace.

\section{The Present Study}

In this study, I answered Potter et al. (2019)'s call to investigate how personal and contextual factors intersect, and lead to discrimination. In particular, I focused on the 
interactive effects of age, gender, and occupation in the recruitment and hiring setting. I chose these personal factors (i.e., age and gender) and contextual factors (i.e., recruitment for software engineers and nurses) for the following reasons.

First, as the recruitment setting acts as the first barrier for older individuals from entering the workforce, it is important to explore this arena of employment settings (Drydakis et al., 2018; Heywood \& Jirjahn, 2016; Riach \& Rich, 2010). As I mentioned above, the older workers (i.e., aged 40 or older) are made up of more than half of the current workforce in the United States (Bureau of Labor Statistics, 2019b). Moreover, age discrimination against old job applicants has been found in several different industries (e.g., Drydakis et al., 2018; Riach \& Rich, 2010). Yet, the high-tech and healthcare industries, where millions of jobs exist, have never been explored for discriminatory outcomes. Thus, the present study serves to address this gap in the current literature.

Second, as noted earlier, a software engineer is a typical occupation in the high-tech industry, whereas a nurse is a typical occupation in the healthcare industry. Moreover, both software engineers and nurses are single-gender-dominant occupations, which are projected to grow much faster than average within the next 10 years (Bureau of Labor Statistics, 2019a, 2019d, 2019e). Recruitment discrimination in these two occupations may further harm the workplace diversity, which, in turn, might lead to negative outcomes for organizations and the society.

Additionally, despite the fact that Asian is the largest population in the labor force, who are highly educated (i.e., holding a bachelor's degree and higher, U.S. Bureau of 
Labor Statistics, 2019c), there is a lack of research attention on this population. Especially important to note is that the present study focused on two high-skilled professions (i.e., software engineer and nurse) that usually require a bachelor's degree. Thus, this study contributes to the literature by using Asian job applicants as stimuli. Lastly, according to prior research on intersectionality, Potter et al. (2019) suggested that multiple factors interact with one another, contributing to complex disparities such that age as one dimension of job applicants' identity may interact with another dimension of identity (i.e., gender) to exert different effects in hiring evaluations (e.g., job suitability, interpersonal skills) and selections (Posthuma \& Campion, 2009; Potter et al., 2019).

In summary, this study aims to address the above gaps in literature by examining how gender may act as a moderator of workplace ageism for two different occupations (i.e., software engineer and nurse) through testing the two hypotheses and answering the research question listed above. 


\section{Method}

\section{Overview}

Using a 4 × 2 × 2 (Ratee Pair Combinations x Occupations x Orders of Applicants) incomplete factorial design (shown in Table 1), the current study investigated the effects of the age and gender of hypothetical job applicants and occupations applied (i.e., software engineer and nurse) on the ratings of job suitability and selection decisions. The first factor is an incomplete between-subjects factor and is a variation of a combination of two applicants from a pool of four who differed in age (young vs. old) and gender (female vs. male). The order of applicants was also counterbalanced. Overall, the current research can be viewed as four different $2 \times 2 \times 2$ (Applicants x Occupations x Orders of Applicants) incomplete mixed factorial designs.

Table 1.

Experimental Design Diagram

Software Engineer Nurse

\begin{tabular}{|c|c|c|c|}
\hline $\begin{array}{l}\text { Young Woman vs. } \\
\text { Old Woman }\end{array}$ & $\begin{array}{l}\text { Old Woman vs. } \\
\text { Young Woman }\end{array}$ & $\begin{array}{l}\text { Young Woman vs. } \\
\text { Old Woman }\end{array}$ & $\begin{array}{l}\text { Old Woman vs. } \\
\text { Young Woman }\end{array}$ \\
\hline $\begin{array}{l}\text { Young Man vs. } \\
\text { Old Man }\end{array}$ & $\begin{array}{l}\text { Old Man vs. } \\
\text { Young Man }\end{array}$ & $\begin{array}{l}\text { Young Man vs. } \\
\text { Old Man }\end{array}$ & $\begin{array}{l}\text { Old Man vs. } \\
\text { Young Man }\end{array}$ \\
\hline $\begin{array}{l}\text { Young Woman vs. } \\
\text { Old Man }\end{array}$ & $\begin{array}{l}\text { Old Man vs. } \\
\text { Young Woman }\end{array}$ & $\begin{array}{l}\text { Young Woman vs. } \\
\text { Old Man }\end{array}$ & $\begin{array}{l}\text { Old Man vs. } \\
\text { Young Woman }\end{array}$ \\
\hline $\begin{array}{l}\text { Young Man vs. } \\
\text { Old Woman }\end{array}$ & $\begin{array}{l}\text { Old Woman vs. } \\
\text { Young Man }\end{array}$ & $\begin{array}{l}\text { Young Man vs. } \\
\text { Old Woman }\end{array}$ & $\begin{array}{l}\text { Old Woman vs. } \\
\text { Young Man }\end{array}$ \\
\hline
\end{tabular}




\section{Participants}

A total of 309 adult participants from the United States completed an online survey via Amazon's MTurk. They received average 30 cents for taking part in the study. A total of 59 subjects were excluded from further analysis because they failed to respond correctly to (a) attention-check items, (b) manipulation-check items or (c) both attentioncheck and manipulation check items. Hence, the final sample consisted of 250 subjects.

In the final sample, 123 participants self-identified as women (49.2\%) and 127 participants self-identified as men (50.8\%). Despite the fact that the third option (i.e., others) was provided, none of the participants chose this option for their self-identified gender information. With regards to race, the majority of the participants $(72.4 \%)$ were White, followed by Black (9.6\%), Asian (6.8\%), two or more races (5.2\%), Hispanic (4.4\%), American Indian (1.2\%), and some other race $(0.4 \%)$. In comparison to the data from U. S. Census Bureau (2018), this sample was for the most part representative of the U.S. population in terms of gender and race (with the exception that Hispanic population was underrepresented; i.e., $4.4 \%$ in the sample vs. $18.3 \%$ in the U.S. population; and two or more race was overrepresented; i.e., $5.2 \%$ in the sample vs. $2.7 \%$ in the U.S. population).

The age of participants ranged from 19 to 71 years $(M=35.75 S D=10.96)$. Moreover, all the participants had an average of 13.96 years of work experience $(S D=$ 10.02). Among them, $88 \%$ reported that they were working at the time of data collection and $58.8 \%$ of them had made a hiring decision in their job before. 


\section{Procedure}

The experiment was composed of 16 different conditions and participants were exposed to only one condition. These 16 conditions were created through Qualtrics survey and the Qualtrics survey links were distributed via Amazon's MTurk. Criteria were set through Amazon's MTurk to ensure that all the participants were from the United States, they were at least aged 18 when they participated in the study, and each of them could only complete the survey once.

At the beginning of the survey, participants were instructed to imagine that they would serve as a hiring manager to recruit college graduates from a university in northern California. They were told to review the resumes of two hypothetical job applicants for an entry-level position one at a time. After reviewing each job applicant's profile, participants were asked to make evaluations on job suitability and interpersonal skills of that job applicant. After completing both job applicants' evaluations, participants were then instructed to make their final hiring decisions, that is, (a) to select one out of the two job applicants they had reviewed for the job, and (b) to recommend which job applicant to be hired as a full-time employee or as a temporary employee, assuming there were only one open full-time position and one open temporary position.

Finally, participants filled out some demographic information about themselves and submitted survey codes for approval of their Human Intelligence Tasks (HITs) on Amazon's MTurk to receive about 30 cents each as a compensation for completing the survey. All the responses were recorded on Qualtrics. On average, it took participants about three to five minutes to complete the questionnaire. 


\section{Experimental Manipulations and Stimulus Materials}

Age and gender. In order to vary applicant age and gender, a photograph was attached to the profile of each of the four hypothetical job applicants. These photographs differed in terms of age (young vs. old) and gender (male vs. female). Additionally, every effort was made to equate the two stimulus persons in each condition on a basis of their professional appearance (e.g., attire, facial expression).

A pilot study was conducted to ensure the effect of age (i.e., the main research focus) as planned. More specifically, all the four photographs (i.e., stimuli) were pilot-tested to examine whether the manipulation of job applicants' age was effective. A total of 41 individuals participated in the pilot study. They were diverse in terms of race (i.e., $34 \%$ Asian, 31\% Hispanic, $20 \%$ White, and $15 \%$ two or more races) but a majority of them was female (i.e., 70\%). Twenty people viewed a matched pair (one woman and one man) of younger applicants' photographs and 21 people viewed another matched pair (one woman and one man) of older applicants' photographs. All of them were asked to select their response from five age choices (i.e., "21 - 30"; "31 - 40”; "41 - 50"; "51 - 60”; and “60+").

Among the 20 participants who viewed the matched pair of younger applicants' photographs, $70 \%$ of them perceived the younger female job applicant to be aged 21 to 30, whereas the rest perceived her as aged 31 to 40 . Moreover, $75 \%$ of them perceived the younger male job applicant to be aged 21 to 30 , whereas the rest perceived him as aged 31 to 40. In contrast, for those viewed the matched pair of older applicants' photographs, $57 \%$ of 21 participants perceived the older female job applicant to be aged 
41 to $50,29 \%$ perceived her as aged 51 to 60 , and only $14 \%$ perceived her as aged 31 to 40. Among these 21 participants, $43 \%$ of them perceived the older male job applicant to be aged 41 to $50,29 \%$ perceived him as aged 51 to 60 , and $29 \%$ perceived him as aged 31 to 40 . Hence, the age effect of the stimuli was ensured. In other words, the age manipulation was effective as intended in the pilot study.

As mentioned above, the main purpose of this study was to investigate the age effect and each participant rated two job applicants. Therefore, the selection of the two applicants from the pool of four was at least one younger applicant and one older applicant with possible pairings of a single gender or both genders. Thus, it resulted in four different ratee-pair combinations: (a) a younger woman vs. an older woman, (b) a younger man vs. an older man, (c) a younger woman vs. an older man, and (d) a younger man vs. an older woman. Participants were randomly assigned to one of these four rateepair combinations.

In order to control for potential order effects, the presentation order of each pair of job applicants was counterbalanced. In other words, half of the participants in each condition were presented with two job applicants in the order specified (i.e., ratee-pair combinations a through d), and the other half were presented with the applicants in a reverse order.

Occupation. As noted earlier, participants were given two hypothetical job applicants' profiles to review one at a time. Each profile contained information of job applicant's name, school name, start and graduation dates, education level, major, grade point average (GPA), job objective, previous work experience, and extracurricular 
activities. The format of an applicant profile was created, imitating a real student profile from the career center website of the university where the study was conducted so as to create a more realistic job applicant profile with a photograph attached to it.

Each of the four job applicant types (i.e., a younger man, an older man, a younger woman, and an older woman) had his or her own profile with different names and headshot photographs. Except these two (i.e., names and photographs), the information was equated across all the profiles for the four job applicant types within the same occupation (i.e., either software engineer or nurse). In addition, each job applicant (e.g., a younger woman) had two profiles. That is, one is prepared for the software engineer position and the other is for the nurse position. Accordingly, it resulted in eight sets of job applicant profiles.

To put it another way, within the same occupation (e.g., software engineer), four sets of job applicant profiles were created with effort that all their qualifications equated. More specifically, for example, all four job applicants who applied for the software engineer position had the equivalent qualifications such as their educational attainment, relevance of education for the occupation, length and nature of prior work experience, and type of extracurricular activities (e.g., campus organizations). All applicants were depicted as fresh graduates from the same university, holding a bachelor's degree, having one previous on-campus job (e.g., customer service at Starbucks or bookstore), being involved in the same student organizations, and having the same job objective (e.g., "looking for an entry level software engineer position"). 
Likewise, another four sets of profiles were also created in the same manner with the other occupation (e.g., nurse) so that job applicants' majors, extracurricular activities and job objectives matched the positions they applied for. For instance, job applicants who majored in software engineering applied for a software engineer position, whereas job applicants who majored in nursing applied for a nursing position. Furthermore, in the survey instructions for participants, the two occupations were emphasized. That is, the words "software engineer" or "nurse" were bolded and highlighted in dark blue rather than the default black color so as to make it more salient for participants to factor in the occupation types. In this way, two different occupations (i.e., software engineer vs. nurse) in two industries (high-tech vs. healthcare) were constructed.

\section{Measures}

Job suitability. Job suitability was measured with a 3 -item summated scale. Sample items were, job applicant's name (e.g., Jon) "is suited for the job" and "has the necessary skills and abilities to perform the job." Participants were asked to indicate the extent to which they agreed with each statement on a 7-point Likert scale, ranging from 1 (strongly disagree) to 7 (strongly agree). The higher the scores on the measure, the greater the perceived suitability of the applicant. Cronbach's alpha $(\alpha)$, computed separately for each of the four types of applicants (e.g., a younger man), ranged from .81 to .88 .

Interpersonal skills. Interpersonal skills were measured using five items, also with a 7-point Likert scale $(1=$ strongly disagree, $7=$ strongly agree $)$. Examples of statements were, job applicant's name (e.g., Jane) "has the ability to work effectively with others" and "would treat others with respect." Higher scores indicated that participants perceived 
the job applicant had better interpersonal skills. Cronbach's alpha ( $\alpha$ ), computed separately for each of the four types of applicants (e.g., a younger woman), ranged from .87 to .91 .

Hiring decisions. Hiring decisions were measured with a questionnaire that asked participants to select one out of the two applicants they believed to be more qualified for the job and to decide which one to be hired as a full-time employee and the other being hired as a temporary contractor.

Attention and manipulation check. One attention-check question was embedded in each evaluation questionnaire followed by one job applicant profile. As each participant reviewed two job applicants and made evaluations for both of them, there were two same attention-check questions (i.e., "Please select somewhat disagree.") in each data set.

One bipolar adjective (i.e., young vs. old) was used to assess the effectiveness of the age manipulation, using 7-point Likert scale. The higher the scores were, the older the job applicants were perceived.

\section{Analyses}

This study used t-test and Chi-square test to analyze the hypotheses of the present study. As discussed in the overview section, the current study can be considered as four 2 x 2 x 2 (Applicants x Occupations x Orders of Applicants) incomplete mixed factorial design. Before testing the hypotheses, data were analyzed to examine whether the presentation order of job applicants influenced the ratings of job suitability and interpersonal skills (i.e., whether there was an order effect). If there was no order effect, the data were combined to be analyzed as a $2 \times 2$ (Applicants $x$ Occupations) mixed 
factorial design. All the tests of the hypotheses were conducted by using a Type I error rate of .05. Data were analyzed with SPSS (version 25). 


\section{Results}

\section{Attention and Manipulation Check}

A total of 25 participants failed to respond correctly as required for the attention check and among whom, seven of them also failed the age manipulation check. Data of these 25 respondents were discarded from further analyses. Furthermore, 34 respondents failed to perceive the age of job applicants as intended. For example, they rated the young job applicant as older than the old job applicant. In other words, these participants failed the manipulation check of age. Hence, these 34 data were also removed. In sum, if participants failed any of the attention and/or manipulation checks, their data were excluded from further analyses. Thus, the final sample was composed of 250 subjects.

\section{Order Effects}

As noted earlier, job applicants' profiles were shown in a counterbalanced order to control for possible order effects. Results of all the independent samples t-tests on the measured variables showed that the order of presentation of stimulus materials did not affect any of the study conditions. Therefore, the data were compiled as eight pairs of repeated-measures (e.g., a younger man vs. an older woman in high-tech industry vs. healthcare industry).

\section{Tests of Hypotheses and Research Question}

Job suitability and interpersonal skills. Participants rated job applicants on job suitability and interpersonal skills. Table 2 displays descriptive statistics for these two variables as a function of pairs of two applicants. As noted earlier, there were eight 
combinations of pairs of applicant types and occupations based on four ratee-pair conditions for each of two occupations.

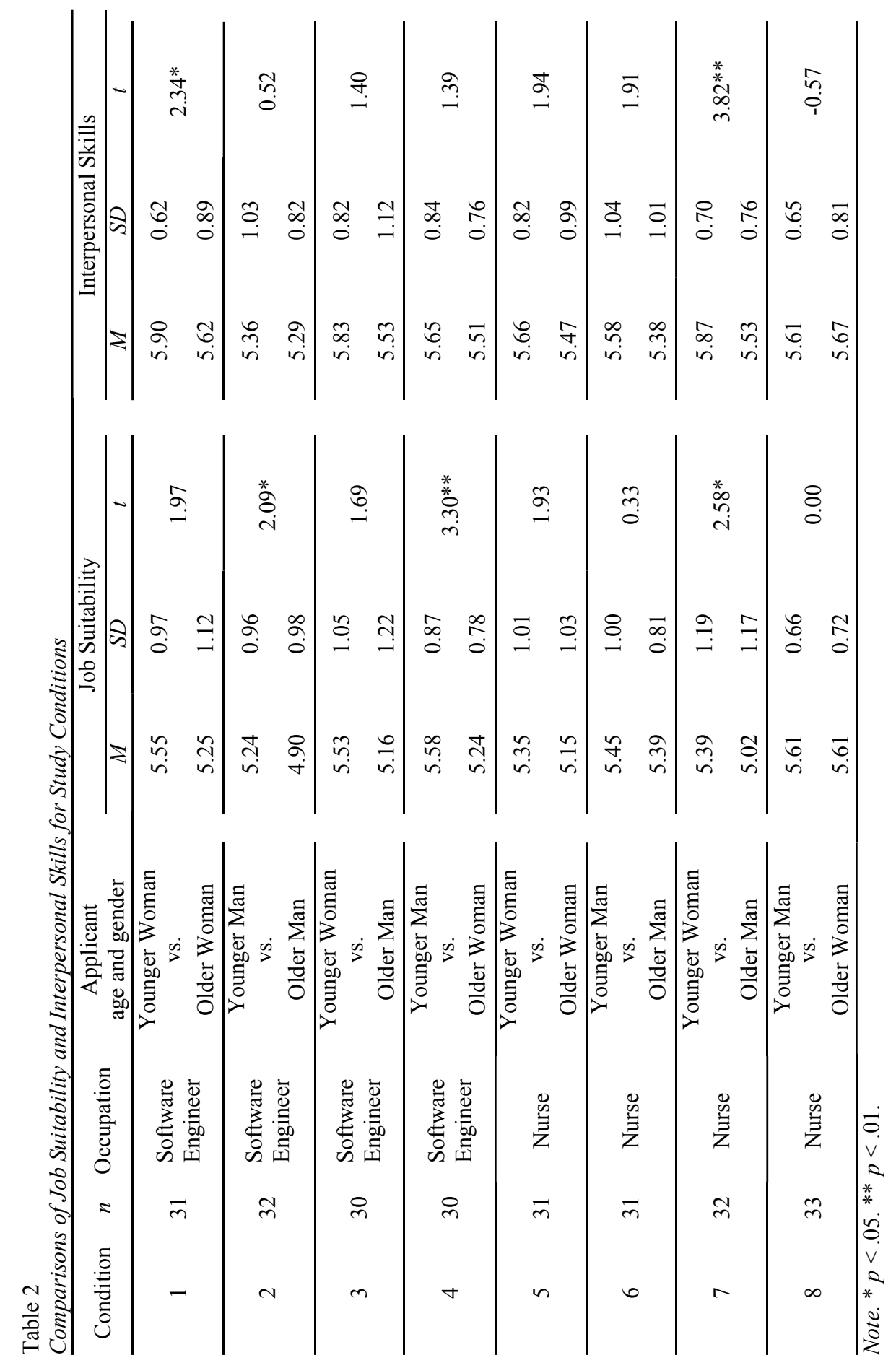




\section{Age effect in two occupations (software engineer and nurse). Hypothesis 1}

predicted that job applicants' age would be stronger for software engineers than for nurses. More specifically, when the gender was held constant (i.e., a younger woman vs. an older woman, a younger man vs. an older man), if both younger and older job applicants applied for a software engineering job, the younger applicant would be rated higher on job suitability (H1a) and interpersonal skills (H1b) than the older job applicant, whereas if the two job applicants apply for a nursing job, the ratings of job suitability (H1c) and interpersonal skills (H1d) would be similar for both the younger and older applicants. This hypothesis was tested in the conditions where two applicants were of the same gender but differed in age. There were four such conditions: one comparing older and younger female applicants, and the other comparing older and younger male applicants, either for the occupation of software engineer (Condition 1 and 2) or for the occupation of nurse (Condition 5 and 6).

For the software engineering job, Condition 1 compared younger and older female job applicants in terms of their ratings of job suitability and interpersonal skills. Results showed that the younger female job applicant $(M=5.55, S D=0.98)$ and the older female job applicant $(M=5.25, S D=1.12)$ did not differ significantly on the ratings of job suitability, $t(30)=1.97, p=.058, d=0.35$. Although the result was not statistically significant, the direction of the mean difference was consistent with H1a. With regards to interpersonal skills, as expected, the younger female job applicant $(M=5.90, S D=0.62)$ was rated significantly higher than the older female job applicant $(M=5.62, S D=0.89)$, $t(30)=2.34, p=.026, d=0.41$. 
Condition 2 compared younger and older male job applicants for the ratings of job suitability and interpersonal skills for the same occupation (i.e., software engineers). Results showed that the younger male applicant $(M=5.24, S D=0.96)$ was rated significantly higher than the older male applicant $(M=4.90, S D=0.98)$ for job suitability, $t(31)=2.09, p=.045, d=0.37$, but not for interpersonal skills, $t(31)=0.52, p$ $=.604, d=0.10$.

In contrast, Condition 5 compared younger and older female job applicants while Condition 6 compared younger and older male job applicants, regarding the ratings of job suitability and interpersonal skills for the nursing job. Results showed that none of the paired comparisons were statistically significant (shown as Table 2).

Therefore, these results showed partial support for Hypothesis 1. That is, when the gender of job applicants was the same, the age discrimination seemed to be stronger for software engineers than for nurses.

Interaction among age, gender and occupation. Hypothesis 2 predicted that age, gender and occupation would interactively influence the recruitment decision-making on suitability ratings, interpersonal skills, and selections (i.e., perceived qualification and employment terms). More specifically, as for a high-tech job (i.e., software engineer), when a younger man and an older woman were compared, the younger man would be rated higher on (H2a) job suitability and (H2b) interpersonal skills, (H2c) selected more often for the job, and (H2d) more likely to be hired as a full-time employee than his competitor (i.e., the older woman). By contrast, in regard to a healthcare job (i.e., nurse), when a younger woman competed against an older man, the younger woman would be 
rated higher on (H2e) job suitability and (H2f) interpersonal skills, $(\mathrm{H} 2 \mathrm{~g})$ considered more qualified (i.e., being selected more), and (H2h) more likely to be hired as a full-time employee than the older man.

This hypothesis was tested in the conditions where the applied occupations were different (i.e., software engineer and nurse) and the two job applicants differed in both age and gender, that is, a younger female job applicant versus an older male job applicant (Conditions 3 and 7), and a younger male job applicant versus an older female job applicant (Conditions 4 and 8).

As expected, as for the software engineering job, when a younger man and an older woman were compared (Condition 4), the younger man $(M=5.58, S D=0.87)$ was rated higher than the older woman $(M=5.24, S D=0.78)$ on job suitability, $t(29)=3.30, p=$ $.003, d=0.61$. Thus, H2a was supported. In addition, as shown in Table 3 and Figure 1, the results of $\chi_{2}$ tests revealed that the younger man (73\%) was selected more often than the older woman $(27 \%), \chi_{2}(1, N=30)=6.53, p=.011$; and he $(77 \%)$ was hired more often as a full-time employee than her $(23 \%), \chi_{2}(1, N=30)=8.53, p=.003$. In other words, in comparison to the older female job applicant, the younger male job applicant was selected more often $(\mathrm{H} 2 \mathrm{c})$ and was more likely to be hired as a full-time employee (H2d). Hence, H2c and H2d were also supported. However, the ratings of interpersonal skills for the younger man $(M=5.65, S D=0.84)$ did not differ from those for the older woman $(M=5.51, S D=0.76), t(29)=1.39, p=.177, d=0.24$. Thus, $\mathrm{H} 2 \mathrm{~b}$ was not supported. In addition, when a younger woman and an older man were compared for the 
software engineer job (Condition 3), none of the results were statistically significant (shown as Table 2 and Table 3 )

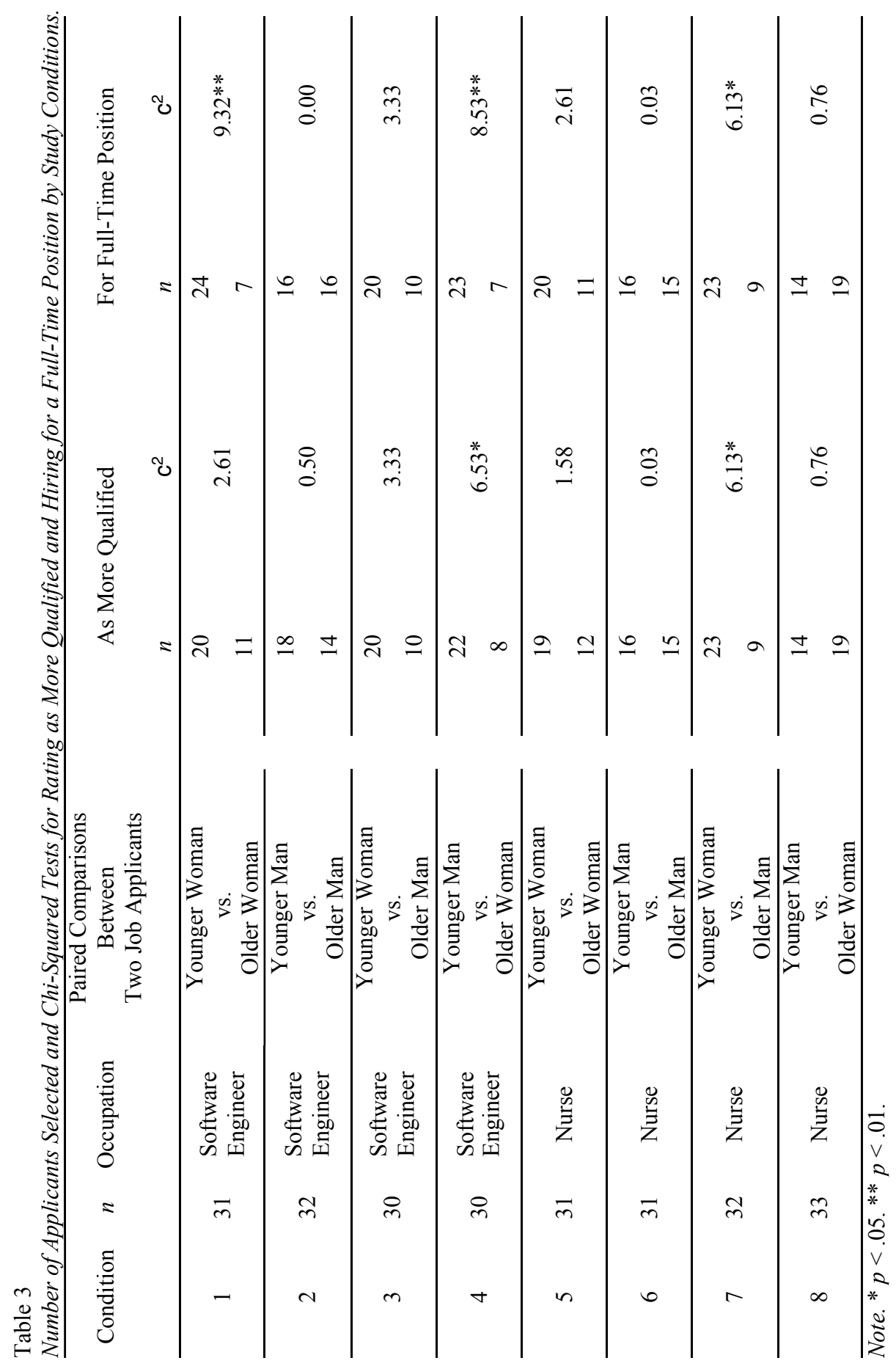




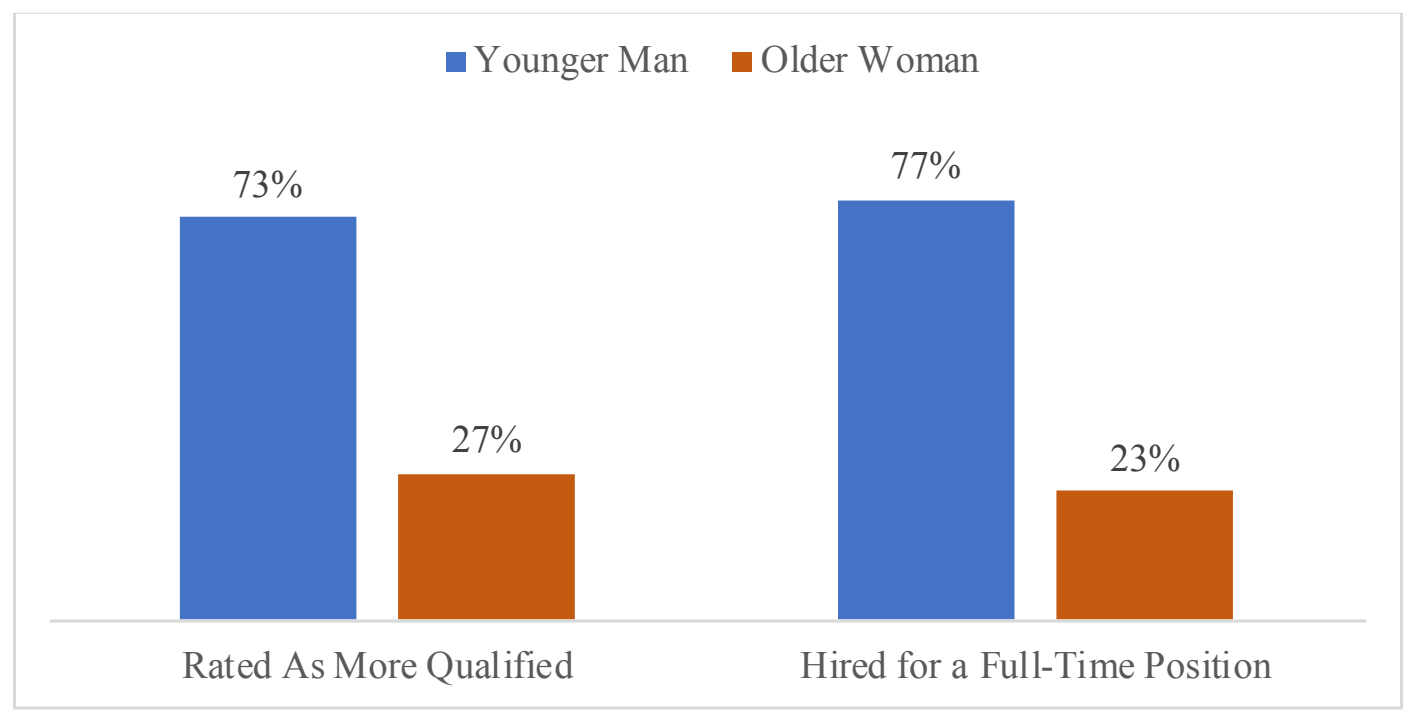

Figure 1. Job applicants selected to be hired as software engineers.

Similarly, as predicted, in regards to nursing job applicants, when a younger woman and an older man were compared (Condition 7), the younger woman was more rated higher on (H2e) job suitability and (H2f) interpersonal skills; (H2g) considered more qualified (i.e., being selected more); and (H2h) more likely to be hired as a full-time employee than the older man. More specifically, as shown in Table 2, regarding job suitability for being a nurse, the younger woman $(M=5.39, S D=1.19)$ was rated significantly higher than the older man $(M=5.02, S D=1.17), t(29)=2.58, p=.015, d=$ 0.46. This result supported H2e. Moreover, the younger woman $(M=5.87, S D=0.70)$ was also rated significantly higher than the older $\operatorname{man}(M=5.53, S D=0.76)$ on interpersonal skills, $t(29)=3.82, p=.001, d=0.69$. Additionally, as shown in Table 3 and Figure 2, the results of $\chi_{2}$ tests revealed that the young woman (72\%) was selected more often, and was hired more as a full-time employee than the old man $(18 \%), \chi_{2}(1, N$ $=32)=6.13, p=.013$. Therefore, $\mathrm{H} 2 \mathrm{e}, \mathrm{H} 2 \mathrm{f}, \mathrm{H} 2 \mathrm{~g}$, and H2h were all supported. Further, 
when a younger man and an older woman were compared as job applicants of nurses (Condition 8), none of the results were statistically significant (shown as Table 2 and Table 3). Accordingly, the majority of Hypothesis 2 was fully supported except one $(\mathrm{H} 2 \mathrm{~b})$.

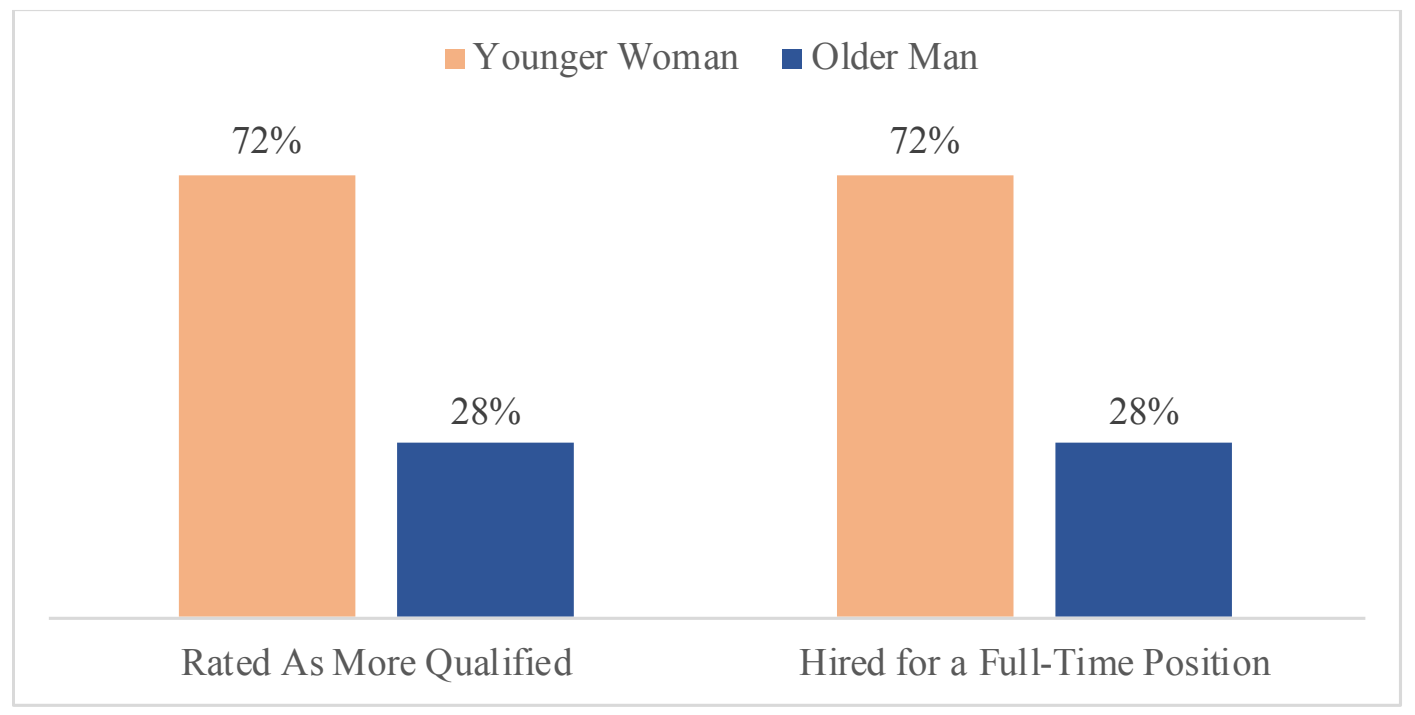

Figure 2. Job applicants selected to be hired as nurses.

Lastly, the above results (i.e., Condition 3 and Condition 8) also provided an answer to the research question. More specifically, as for job applicants of software engineers, there were no significant difference in terms of the ratings and selections between a younger woman and an older man. Likewise, the same statistical results also applied to the comparison between a younger man and an older woman as nurse job applicants. Accordingly, these findings provided an answer to the research question that the applicants' gender and the occupation they applied concurrently moderated the effect of job applicants' age in the hiring setting. In other words, the effects of gender and occupation might counteract to diminish age discrimination in the recruitment setting. 


\section{Discussion}

Prior research indicates that older job seekers may experience discrimination because of their age in the hiring setting due to workplace age stereotypes (e.g., Baert et al., 2016; Posthuma \& Campion, 2009; Vasconcelos, 2015). At the same time, researchers (e.g., Fisher et al., 2017; Posthuma \& Campion, 2009; Potter et al., 2019) posit that other personal and contextual factors (e.g., gender, occupation) may interact to exacerbate or diminish employment age discrimination. Therefore, the goals of this study were to examine the moderating effects of gender and occupation on age discrimination in the recruitment setting. More specifically, this study explored two single-gender-dominant (i.e., either male-dominant or female-dominant) occupations (i.e., software engineer and nurse) to test the interaction effects of age, gender, and occupation in the hiring process.

Consistent with the findings of previous research (e.g., Baert et al., 2016; Drydakis et al., 2018; Heywood \& Jirjahn, 2016), the results of the current study demonstrated that when an older job applicant competed against a younger job applicant, while gender and occupation were held constant, the older job applicant experienced a disadvantage because of his or her age in comparison to the younger job applicant. More specifically, except for the condition where an older woman competed against a younger man for the nursing job, in general, the older job applicant was rated lower on job suitability and interpersonal skills, was perceived as less qualified for the job, and was selected less for the full-time position than the younger job applicant. The results occurred especially in a context where job applicants were depicted as new college graduates with similar past work experience. These findings were also congruent with the findings of Riach and Rich 
(2010) that the older job applicants were at a higher risk of being discriminated against than their younger competitors in the case of "new graduates." The results are also aligned with Hanrahan and colleagues' (2017) rationale for why older people may become the target of exclusion as new employees because they do not match with the age norms of trainees or mentees and/or violate the positive assumption or expectation about them that older individuals would be more skilled and experienced. These findings indicate that even a positive age stereotype (e.g., being perceived as more skilled and experienced) of older people could backfire against them in a certain situation (Hanrahan et al., 2017).

Furthermore, the results of this present study supported Hypothesis 1 which stated that there would be an interaction of age and occupation on the hiring decision-making. More specifically, the results showed that when gender was held constant, job applicants of software engineers encountered somewhat more age discrimination for being old than those of nurses. This finding is consistent with the argument of other researchers (e.g., Hanrahan et al., 2017; Posthuma \& Campion, 2009; Slay Ferraro et al., 2018; Vasconcelos, 2015) that older job seekers face more challenges in obtaining employment opportunities in the high-tech industry because of age stereotyping. It also aligns with the anecdotal evidence that big tech companies such as Google and Facebook discriminate against older job applicants (i.e., aged 40 and older; Hern, 2019; Terrell, 2019).

The results also suggested that, consistent with Hypothesis 2 which stated that age, gender and occupation would interact to influence hiring decision-making such that with regard to these two occupations (i.e., software engineer and nurse), there would be both 
age and gender discrimination in the hiring context. More specifically, when an older woman and a younger man competed against each other for a software engineer role, the older female job applicant experienced double discrimination (i.e., age and gender) as she received lower rating of job suitability, was perceived as less qualified, and was less likely to be chosen for the full-time position than the younger male job applicant.

In a similar vein, when an older man and a younger woman competed against each other as candidates of a nursing job, the older man experienced double discriminations as he was rated lower on both job suitability and interpersonal skills, was selected less often, and was less likely to receive a full-time employment than the younger woman. These findings are consistent with the theories of age stereotyping (e.g., Fisher et al., 2017; Posthuma \& Campion, 2009; Riach \& Rich, 2010; Vasconcelos, 2015) and occupational gender biases (Kay et al. 2015). They also align with the dual discrimination approach, reflecting the simple additive effects of age and gender biases (i.e., duel stigmatized identities; Hosoda et al., 2003; Potter et al., 2019). More importantly, the results are also in line with Drydakis and colleagues' (2018) findings and Potter and colleagues' (2019) assertion that one aspect of identity (e.g., age) might intensify the experienced inequalities because of another aspect of identity (e.g., gender).

Nonetheless, according to prior research on the intersectionality approach, Potter et al. (2019) have pointed out that reference group is another key factor influencing the inequalities individuals might have experienced. In other words, individuals with multiple identities (i.e., age and gender in this case) might experience both advantages and 
disadvantages depending on their reference group, especially when the contextual factor (i.e., the occupations job applicants applied) is taken into account.

More specifically, the results of this study showed that when an older male job applicant competed against a younger female job applicant for a software engineering job, there were no significant difference between their ratings of job suitability, interpersonal skills, qualifications and the selections for the full-time position. These results indicated that, in comparison to the younger woman, although the older man might have experienced a disadvantage of being old as a new college graduate candidate, he might have experienced an advantage of being male as a software engineer candidate (i.e., consistent with occupational gender stereotype). Likewise, the same argument also applies to the occupation of nurse. That is, when an older female job applicant competed against a younger male counterpart as nursing job candidates, the ratings of their job suitability and interpersonal skills, and the selections for qualification and for the fulltime position did not differ significantly because these two job candidates' advantaged and disadvantaged positions due to their age and gender balanced out.

The above results indicated that if an older job applicant's gender (e.g., male) matched with the occupational gender stereotype (e.g., male) and this older applicant competed against another younger job applicant whose gender (e.g., female) did not match with the majority in that specific occupation (e.g., software engineer), the applicant's age may have less adverse impact on the job suitability ratings and other employment related decisions. Thus, these findings provided the first empirical evidence as an answer to the research question, which stated whether the effects of gender and 
occupation could counteract to diminish age discrimination in an employment setting. Taken together, the findings of this study supported the intersectionality approach such that personal factors (i.e., multiple dimensions of social identity such as age, race, and gender) interacted with contextual factors (e.g., being new college graduates and applying for the occupations of software engineer and nurse), along with their reference group, resulting in complex disparities experienced (Potter et al., 2019).

\section{Theoretical Implications}

This study contributed to the empirical literature on workplace ageism by answering several researchers' calls (e.g., Fisher et al., 2017; Posthuma \& Campion, 2009) to examine whether gender and industry acted as moderators of the effect of age on employment-related decisions. Posthuma and Campion (2009) have argued that age might interact with other types of stereotyping such as gender and race. In fact, Drydakis et al. (2018) have examined the moderating effect of race on the relationship between age and hiring decision-making and found that a minority racial status (i.e., Black) exacerbated age discrimination (i.e., being old) in hiring for low-paying jobs. Hence, this study paid research attention to explore how age stereotyping interacted with gender stereotyping, contributing to recruitment disparities, especially considering occupational gender bias (Kay et al., 2015). Put differently, the present study investigated how gender and occupation concurrently moderated the effect of age on hiring evaluations (e.g., job suitability rating) and decisions (e.g., selection for the job).

Additionally, the findings of the present study provided the initial empirical evidence for researchers' assertion (e.g., Posthuma \& Campion, 2009; Slay Ferraro et al., 2018; 
Vasconcelos, 2015) that older individuals might be considered as inappropriate for a high-tech job because of age norms in this industry. Furthermore, this study also addressed the gap in the literature of recruitment age discrimination by focusing on two industries (i.e., high-tech and healthcare) that have never been studied, more specifically, two high-paying jobs (software engineers and nurses).

Furthermore, the current study also answered Drydakis and colleagues' call (2018) to examine whether ageism in the hiring setting was less severe for better-educated people and for occupations of high vacancies where human capital was needed by focusing on the job applicants who had just obtained a bachelor's degree in the majors that prepared for two fast-growing occupations (i.e., software engineer and nurse). Unfortunately, to the contrary, the results of this study revealed that age discrimination in the recruitment setting did not appear to be less for the highly-educated individuals or for the occupations of high vacancies, given that the older applicants, even when they had a college degree and applied for the occupations of high vacancies, still experienced discrimination against them compared to their younger counterparts.

However, it is noteworthy that the reference group also played a significant role in determining whether age discrimination would be exacerbated or diminished. The results of this study provided the empirical evidence that when a job applicant whose characteristics (e.g., age, gender) were categorized as stigmatized identities (e.g., being old and being female for a software engineering job), competed against another job applicant, who enjoyed both privileges of social identities (e.g., being young and being male as a software engineer candidate), the former job applicant experienced more age 
discrimination. In contrast, when two job applicants who possessed social identities that involved both advantages and disadvantages because of their reference group (e.g., a younger male nursing candidate vs. an older female nursing candidate), the two different dimensions of identity (i.e., age and gender) and the setting (i.e., occupation or industry) in which the job applicants were, could counteract to diminish age discrimination. These results are congruent with cumulative research evidence of intersectionality approach (Potter et al., 2019). Thus, these findings also contribute to the growing body of intersectionality literature.

\section{Practical Implications}

In addition to the theoretical implications discussed above, this study also has several important practical implications. The results of the current study provide a better understanding of the factors that might influence hiring decision making (i.e., age and gender of applicants and occupation these applicants applied). In particular, age was a main factor in this study. As mentioned earlier, there would be a larger share of older workers (i.e., aged 55 and above) in the U.S. workforce within the next five years. It is critical to address the issue of workplace age discrimination due to its fundamental influences in both organizations and the society. More importantly, the results of the present study showed that a minority gender status of an occupation (i.e., women as software engineers and men as nurses) intensified age discrimination in the hiring setting. These findings provided evidence that organizations and government agencies needed to develop targeted policies and interventions that would help to reduce biases and ensure fair treatment of all individuals in the society. 
Although there are already federal laws in place (e.g., ADEA of 1967; Title VII of the Civil Rights Act of 1964), EEOC's statistics (e.g., about one million of cases related to age-based and sex-based discriminations received within the past 20 years) indicate that these federal laws or existence of these laws are far from being sufficient for preventing or reducing discrimination in the workplace. Furthermore, prior research on workplace diversity shows that a lack of diversity has a detrimental impact on organizational outcomes such as reduced productivity and company growth (Hanrahan et al., 2017; Posthuma \& Campion, 2009). Therefore, organizations should take actions to address this issue and promote workplace diversity and inclusion. For example, one approach that organizations can adopt is to eliminate job applicant' photographs or names that may stimulate unconscious biases against individuals of multiple stigmatized identities in the initial screening. The reason for this is that in the initial screening, there is usually limited information available (e.g., resumes, cover letters) about the job applicants. Researchers (e.g., Fisher et al. 2017; Posthuma \& Campion, 2009; Vasconcelos, 2015) have contended that stereotypes are more likely to be activated with limited available information. The present study demonstrated that by only manipulating the photographs of job applicants, it could lead to participants' biases against individuals of stigmatized characteristics. At the same time, organizations can also provide training programs (e.g., unconscious bias training) to decision-makers such as recruiters, interviewers and hiring managers to combat these biases (Hosoda et al., 2003).

Furthermore, government agencies can develop policies that encourage organizations to work together to solve the potential problems (e.g., economic and social costs) of an 
aging population through corporate social responsibility. In fact, Cortijo and colleagues (2019) proposed an Acknowledge-Grow-Embrace (AGE) model for organizations to address ageism in the workplace. More specifically, this model involves a three-steps approach. First, organizations should acknowledge that there may be activities and practices that are related to age discrimination within the companies. Second, employers should grow their understanding of current different levels and forms of ageism in their organizations and address these issues accordingly by installing appropriate systems that help to reduce and prevent age bias. Last, organizations should embrace age diversity (i.e., employees of all ages) so that employers can take advantage of diverse thoughts, experiences and skills of their human capitals, contributing to positive organizational outcomes such as better retention and financial performance (e.g., Cortijo et al., 2019; Posthuma \& Campion, 2009; Vasconcelos, 2015). More importantly, organizations can utilize the same strategy to address other areas (e.g., gender, race) of their workplace diversity problems.

\section{Strengths, Limitations, and Future Research}

This study's sample is representative of the U.S. population for the most part as discussed previously. Hence, the findings can be generalized to the employment situation within the United States. Moreover, this current study implemented an experimental approach. The findings can be interpreted as causal effects. That is, age, gender and occupation jointly affected people's hiring decision-making.

Research on recruitment age discrimination often holds job applicants' gender constant (either male or female; e.g., Baert et al., 2016; Drydakis et al., 2018; Riach \& 
Rich, 2010). Hence, one strength of the current study is that it includes the conditions in which job applicants differed in both age and gender. This work is in line with the growing emphasis on intersectionality approach. That is, individuals' different aspects of social identities should not be isolated to examine because multiple dimensions of social identity categories (e.g., age, gender, race) interact with one another, resulting in complex inequalities experienced (Potter et al., 2019). Another strength of this study is that it utilized Asian hypothetical job applicants because prior research has mainly focused on the races of White and Black. Therefore, the present study helps to shed light on this forgotten racial population (i.e., Asian). Future researchers should continue to examine discriminatory factors against marginalized populations.

Nevertheless, there are several limitations in the current study despite its contributions to the employment discrimination literature. This study was conducted in a laboratory setting, using a within-subjects design. Fisher and colleagues (2017) discussed that age became more salient in lab settings where the age of job applicants was a main manipulated factor. However, it is notable that in a real-life scenario, employment decision-makers (e.g., recruiters, hiring managers) face the same circumstance where they need to compare and select job applicants from the same applicant pool (i.e., a within-subjects setting; Ng \& Feldman, 2012; Fisher et al., 2017). Hence, a withinsubjects design is applicable and generalizable to a real-world hiring and selection scenario.

Another concern is that the hiring evaluations and decisions made in the present study may be different from those of actual decision-makers in the organizations. The 
participants in this study might not have experience or training in hiring practices such that they were more likely to make decisions based on their stereotypes of age, gender and occupation than those actual recruiters or hiring managers who went through training to combat their unconscious biases. Yet, it is noteworthy that a majority (i.e., 58.8\%) of participants in this study reported that they had made hiring decisions at work before, which indicated that people with hiring experience might also rely on their stereotypes to make hiring evaluations and decisions in a real-world setting. Furthermore, the current findings were also congruent with what other researchers (e.g., Baert et al., 2016; Drydakis et al., 2018; Riach \& Rich, 2010) had typically found in the field studies of age discrimination.

In addition, this study did not measure workplace age stereotypes (e.g., low motivation and lack of flexibility). Future research could consider integrating these elements into the research design such that it would help to draw conclusions regarding whether and which age stereotypes would correlate with discriminatory practices against older job candidates. In addition, researchers could also consider other intersectionality factors (e.g., race, socioeconomic status) as well in order to expand our knowledge of ageism in the workplace.

\section{Conclusion}

In summary, the findings of the present study showed that gender and occupation might concurrently moderate the effect of age on hiring decision making. More specifically, job applicants' gender (i.e., personal factor) and the occupation they applied for (i.e., contextual factor) could interact with each other to exacerbate or diminish age 
discrimination in the employment context. I hope that the findings, strengths, and limitations of this study will guide future research on the issues related to workplace diversity. 


\section{References}

Armstrong-Stassen, M., \& Schlosser, F. (2011). Perceived organizational membership and retention of older workers. Journal of Organizational Behavior, 32, 319-344. doi.org/10.1002/job.647

Baert, S., Norga, J., Thuy, Y., \& Van Hecke, M. (2016). Getting grey hairs in the labour market. An alternative experiment on age discrimination. Journal of Economic Psychology, 57, 86-101. doi.org/10.1016/j.joep.2016.10.002

Bal, A. C., Reiss, A. E. B., Rudolph, C. W., \& Baltes, B. B. (2011). Examining positive and negative perceptions of older workers: A meta-analysis. The Journals of Gerontology Series B, 66B, 687-698. dx.doi.org/10.1093/geronb/gbr056

Chou, R. J., \& Choi, N. G. (2011). Prevalence and correlates of perceived workplace discrimination among older workers in the United States of America. Ageing and Society, 31, 1051-1070.doi.org/10.1017/S0144686X10001297

Cortijo, V., McGinnis, L. P., Şişli-Ciamarra, E. (2019). The AGE model: Addressing ageism in the workplace through corporate social responsibility. Labor and Society, 22, 197-213. doi.org/10.1111/wusa. 12387

Data USA. (2019). Data USA: Registered nurses. Retrieved from https://datausa.io/profile/soc/registered-nurses

Drydakis, N., MacDonald, P., Chiotis, V., \& Somers, L. (2018). Age discrimination in the UK labour market. Does race moderate ageism? An experimental investigation. Applied Economic Letters, 25, 1-4. doi.org/10.1080/13504851.2017.1290763

Fekedulegn, D., Alterman, T., Charles, L. E., Kershaw, K. N., Safford, M. M., Howard, V. J., \& MacDonald, L. A. (2019). Prevalence of workplace discrimination and mistreatment in a national sample of older U.S. workers: The REGARDS cohort study. SSM - Population Health, 8, 100444. doi.org/10.1016/j.ssmph.2019.100444

Fisher, G. G., Truxillo, D. M., Finkelstein, L. M., \& Wallace, L. E. (2017). Age discrimination: Potential for adverse impact and differential prediction related to age. Human Resource Management Review, 27, 316-327. doi.org/10.1016/j.hrmr.2016.06.001

Haddad, L. M., \& Toney-Butler, T. J. (2019). Nursing shortage. Retrieved from https://www.ncbi.nlm.nih.gov/books/NBK493175/ 
Hanrahan, E. A., Huntoon Lindeman, M. I., \& Finkelstein, L. M. (2017). Discounting seniors: Implications of age stereotypes at work. Translational Issues in Psychological Science, 3, 370-377. doi.org/10.1037/tps0000132

Hern, A. (2019, July 22). Google pays $\$ 11 \mathrm{~m}$ to jobseekers who alleged age discrimination [Web log post]. Retrieved from https://www.theguardian.com/technology/2019/jul/22/google-pays-11m-tojobseekers-who-alleged-age-discrimination

Heywood, J., \& Jirjahn, U. (2016). The hiring and employment of older workers in Germany: A comparative perspective. Journal for Labour Market Research, 49, 349366.

Hosoda, M., Stone, D. L., \& Stone-Romero, E. F. (2003). The interactive effects of race, gender and job type on job suitability ratings and selection decisions. Journal of Applied Social Psychology, 33, 145-178. doi.org/10.1111/j.15591816.2003.tb02077.x

Kay, M., Matuszek, C., \& Munson, S. A. (2015). Unequal representation and gender stereotypes in image search results for occupations. Proceedings of the 33 rd Annual ACM Conference on Human Factors in Computing Systems, USA, 15, 3819-3828. doi: $10.1145 / 2702123.2702520$

Lagacé, M., Van de Beeck, L., \& Firzly, N. (2019). Building on intergenerational climate to counter ageism in the workplace? A cross-organizational study. Journal of Intergenerational Relationships, 17, 201-219. doi.org/10.1080/15350770.2018.1535346

Merton, R. K. (1968). Social theory and social structure. New York; Free Press.

National Council of State Boards of Nursing. (2018). The U.S. Nursing Workforce in 2018 and Beyond. Journal of Nursing Regulation, 8, S3-S6. doi.org/10.1016/S2155-8256(18)30015-2

Ng, T. W. H., \& Feldman, D. C. (2008). The relationship of age to ten dimensions of job performance. Journal of Applied Psychology, 93, 392-423. dx.doi.org/10.1037/0021-9010.93.2.392

Ng, T. W. H., \& Feldman, D. C. (2012). Evaluating six common stereotypes about older workers with meta-analytical data. Personnel Psychology, 65, 821-858. dx.doi.org/10.1111/peps.12003 
Ng, T. W. H., \& Feldman, D. C. (2013). A meta-analysis of the relationship of age and tenure with innovation-related behaviour. Journal of Occupational and Organizational Psychology, 86, 585-616. doi.org/10.1111/joop.12031

Nunez-Smith, M., Pilgrim, N., Wynia, M., Desai, M. M., Jones, B. A., Bright, C., Krumholz, H., \& Bradley, E. H. (2009). Race/ethnicity and workplace discrimination: Results of a national survey of physicians. Journal of General Internal Medicine, 24, 1198-1204. doi: 10.1007/s11606-009-1103-9

Organ, D. W. (1997). Organizational citizenship behavior: It's construct clean-up time. Human Performance, 10, 85-97. doi.org/10.1207/s15327043hup1002_2

Posthuma, R., \& Campion, M. (2009). Age stereotypes in the workplace: Common stereotypes, moderators, and future research directions. Journal of Management, 35, 158-188. doi.org/10.1177/0149206308318617

Potter, L., Zawadzki, M. J., Eccleston, C. P., Cook, J. E., Snipes, S. A, Sliwinski, M. J., \& Smyth, J. M. (2019). The intersections of race, gender, age, and socioeconomic status: Implications for reporting discrimination and attributions to discrimination. Stigma and Health, 4, 264-281. doi.org/10.1037/sah0000099

Riach, P.A., \& Rich, J. (2010). An experimental investigation of age discrimination in the English labor market. Annals of Economics and Statistics, 99/100, 169-185.

Slay Ferraro, H., Prussia, G., \& Mehrotra, S. (2018), The impact of age norms on career transition intentions. Career Development International, 23, 212-229. doi.org/ 10.1108/CDI-06-2017-0110

Terrell, K. (2019, March 20). Facebook reaches settlement in age discrimination lawsuits [Web log post]. Retrieved from https://www.aarp.org/work/working-at-50-plus/info2019/facebook-settles-discrimination-lawsuits.html

Toossi, M., \& Torpey, E. (2017). Older workers: Labor force trends and career options. Retrieved from https://www.bls.gov/careeroutlook/2017/article/olderworkers.htm

Torpey, E. (2014). Healthcare: Millions of jobs now and in the future. Retrieved from https://www.bls.gov/careeroutlook/2014/spring/art03.pdf

U. S. Bureau of Labor Statistics. (2019a). Employed persons by detailed occupation, sex, race, and Hispanic or Latino ethnicity. Retrieved from https://www.bls.gov/cps/cpsaat11.htm 
U. S. Bureau of Labor Statistics. (2019b). Employment status of the civilian noninstitutional population by age, sex and race. Retrieved from https://www.bls.gov/cps/cpsaat03.htm

U. S. Bureau of Labor Statistics. (2019c). Labor force characteristics by race and ethnicity, 2018 (Report No. 1082). Retrieved from https://www.bls.gov/opub/reports/race-and-ethnicity/2018/home.htm

U. S. Bureau of Labor Statistics. (2019d). Occupational outlook handbook, registered nurses. Retrieved from https://www.bls.gov/ooh/healthcare/registered-nurses.htm

U. S. Bureau of Labor Statistics. (2019e). Occupational outlook handbook, software developers. Retrieved from https://www.bls.gov/ooh/computer-and-informationtechnology/software-developers.htm

U. S. Equal Employment Opportunity Commission. (2016). Diversity in high tech. Retrieved from https://www.eeoc.gov/eeoc/statistics/reports/high-tech

U. S. Equal Employment Opportunity Commission. (2020). Charge Statistics (Charges filed with EEOC), FY 1997 - FY 2019. Retrieved from https://www.eeoc.gov/eeoc/statistics/enforcement/sex.cfm

U.S. Government Accountability Office. (2012). Unemployed older workers: Many experience challenges regaining employment and face reduced retirement security. Retrieved from http://www.gao.gov/assets/600/590408.pdf

Vasconcelos, A. F. (2015). Older workers: Some critical societal and organizational challenges. Journal of Management Development, 34, 352-372. doi.org/10.1108/JMD-02-2013-0034

Wanberg, C. R., Kanfer, R., Hamann, D. J., \& Zhang, Z. (2016). Age and reemployment success after job loss: An integrative model and meta-analysis. Psychological Bulletin, 142, 400 - 426. doi: 10.1037/bul0000019 


\section{Appendix}

\section{Hiring Evaluations and Decisions Questionnaire}

\section{Manipulation Check:}

Please pick the checkbox that best describes your general impressions according to the resume you just reviewed.
Young
Old

Job Suitability:

Please indicate the extent to which you agree or disagree with the statements below.

1. Job applicant's name (e.g., Jane, Jon, Cynthia, Roger) is suited for the job.

- Strongly disagree

- Disagree

○ Somewhat disagree

- Neither agree nor disagree

○ Somewhat agree

○ Agree

○ Strongly agree

2. Job applicant's name (e.g., Jane, Jon, Cynthia, Roger) has the necessary skills and abilities to perform the job.

○ Strongly disagree

○ Disagree

- Somewhat disagree

- Neither agree nor disagree

○ Somewhat agree

○ Agree

- Strongly agree

3. Job applicant's name (e.g., Jane, Jon, Cynthia, Roger) would be successful at this job.

- Strongly disagree

○ Disagree

- Somewhat disagree 
- Neither agree nor disagree

○ Somewhat agree

○ Agree

$\circ$ Strongly agree

\section{Attention Check:}

Please indicate the extent to which you agree or disagree with the statements below.

4. Please select "Somewhat disagree".

- Strongly disagree

- Disagree

- Somewhat disagree

- Neither agree nor disagree

○ Somewhat agree

- Agree

$\circ$ Strongly agree

\section{Interpersonal Skills:}

Please indicate the extent to which you agree or disagree with the statements below.

5. Job applicant's name (e.g., Jane, Jon, Cynthia, Roger) has the ability to work effectively with others.

- Strongly disagree

- Disagree

- Somewhat disagree

- Neither agree nor disagree

- Somewhat agree

- Agree

$\circ$ Strongly agree

6. Job applicant's name (e.g., Jane, Jon, Cynthia, Roger) has the ability to get along with others.

- Strongly disagree

- Disagree

- Somewhat disagree

- Neither agree nor disagree 
- Somewhat agree

○ Agree

$\circ$ Strongly agree

7. Job applicant's name (e.g., Jane, Jon, Cynthia, Roger) would treat others with respect.

- Strongly disagree

- Disagree

- Somewhat disagree

- Neither agree nor disagree

- Somewhat agree

- Agree

$\circ$ Strongly agree

8. Job applicant's name (e.g., Jane, Jon, Cynthia, Roger) would show concern for others.

- Strongly disagree

○ Disagree

- Somewhat disagree

- Neither agree nor disagree

- Somewhat agree

○ Agree

$\circ$ Strongly agree

9. Job applicant's name (e.g., Jane, Jon, Cynthia, Roger) would demonstrate effective communication skills.

- Strongly disagree

○ Disagree

- Somewhat disagree

- Neither agree nor disagree

- Somewhat agree

- Agree

- Strongly agree 
Hiring Decisions

10. (a) Please select the job applicant you think is the more qualified as a software engineer. (Participants select one out of the two job applicants as below combinations).

\begin{tabular}{ccc}
\hline Combination & Job Applicant 1 & Job Applicant 2 \\
1 & Jane & Cynthia \\
2 & Cynthia & Jane \\
3 & Jon & Roger \\
4 & Roger & Jon \\
5 & Jane & Roger \\
6 & Roger & Jane \\
7 & Jon & Cynthia \\
8 & Cynthia & Jon \\
\hline
\end{tabular}

(b) Please select the job applicant you think is the more qualified as a nurse.

(Participants select one out of the two job applicants as below combinations).

$\begin{array}{ccc}\text { Combination } & \text { Job Applicant 1 } & \text { Job Applicant } 2 \\ 1 & \text { Jane } & \text { Cynthia } \\ 2 & \text { Cynthia } & \text { Jane } \\ 3 & \text { Jon } & \text { Roger } \\ 4 & \text { Roger } & \text { Jon } \\ 5 & \text { Jane } & \text { Roger } \\ 6 & \text { Roger } & \text { Jane } \\ 7 & \text { Jon } & \text { Cynthia } \\ 8 & \text { Cynthia } & \text { Jon }\end{array}$


11. Suppose that there are only ONE full-time position and only ONE temporary position available. Please decide which candidate will be hired for each position. Please type either "full-time" (F) or "temporary" (T) in each box. (Participants view each below combination).

\begin{tabular}{ccc}
\hline Combination & Job Applicant 1 & Job Applicant 2 \\
1 & Jane & Cynthia \\
2 & Jon & Roger \\
3 & Jane & Roger \\
4 & Jon & Cynthia \\
\hline
\end{tabular}

Demographic Information:

1. Your Gender

- Female

- Male

○ Others

2. Your Age

3. Your Race/Ethnicity. Choose all that apply:

$\square$ African American

$\square$ Asian

$\square$ Latino/a

$\square$ Native American

$\square$ White

$\square$ Others 
4. Are you currently working?

○ Yes

- No

5. How many years of work experience do you have?

6. Have you ever made a hiring decision in your job?

○ Yes

- No 